\title{
How well do the CMIP6 models simulate dust aerosols?
}

Alcide Zhao ${ }^{1.2}$, Claire L. Ryder ${ }^{1}$, Laura J. Wilcox ${ }^{1,2}$

${ }^{1}$ Department of Meteorology, University of Reading, Reading, UK

${ }^{2}$ National Centre for Atmospheric Science, UK

5 Correspondence to: Alcide Zhao (alcide.zhao@ reading.ac.uk)

Abstract. Mineral dust impacts key processes in the Earth system, including the radiation budget, clouds, and nutrient cycles. We evaluate dust aerosols in 16 models participating in the sixth phase of the Coupled Model Intercomparison Project (CMIP6) against multiple reanalyses and satellite observations. Most models, and particularly the multi-model ensemble mean (MEM), capture the spatial patterns and seasonal cycles of global dust processes well. However, large uncertainties and inter-model

10 diversity are found. For example, global dust emissions, primarily driven by model-simulated surface winds, vary by a factor of 5 across models, while the MEM estimate is double the amount in reanalyses. The ranges of CMIP6 model-simulated global dust emission, deposition, burden and optical depth (DOD) are larger than previous generations of models. Models present considerable disagreement in dust seasonal cycles over North China and North America. Here, DOD values are overestimated by most CMIP6 models, with the MEM estimate 1.2-1.7 times larger compared to satellite and reanalysis datasets. Such

15 overestimates can reach up to a factor of 5 in individual models. Models also fail to reproduce some key features of the regional dust distribution, such as dust accumulation along the southern edge of the Himalayas. Overall, there are still large uncertainties in CMIP6 models' simulated dust processes, which feature inconsistent biases throughout the dust lifecycle between models, particularly in the relationship connecting dust mass to DOD. Our results imply that modelled dust processes are becoming more uncertain as models become more sophisticated. More detailed output relating to the dust cycle in future intercomparison

20 projects will enable better constraints of global dust cycles, and enable the potential identification of observationallyconstrained links between dust cycles and optical properties.

\section{Introduction}

Mineral dust, a key component of the Earth system, has important impacts on the global climate and environment through a number of pathways (Mahowald et al., 2010; Gassó et al., 2010; Knippertz and Stuut, 2014; Shao et al., 2011; Mahowald et al., 2014; Kok et al., 2018; Jin et al., 2021). For example, links have been found between dust emissions and Atlantic hurricanes, Amazon Forest fertilisation (Yu et al., 2015), and the African and Indian monsoons (N'Datchoh et al., 2018; Skonieczny et al., 2019; Maharana et al., 2019; Jin et al., 2021). There remain considerable gaps in our understanding of dust throughout its lifecycle (i.e., emission, transport and deposition) due partly to challenges in dust observations (Richter and Gill, 2018), hindering complete understanding and modelling of the complex roles of dust aerosols in the Earth system.

Dust aerosols have been included in global climate and Earth system models since the late 1980s (Shao et al., 2011). These models, with increasingly finer resolutions and more sophisticated model physics and parameterisations, demonstrate certain capabilities in simulating mesoscale to global scale dust events and processes. However, large uncertainties exist in dust simulations stemming from many sources (Evan et al., 2014; Wu et al., 2018, 2020b; Adebiyi and Kok, 2020). For example, incomplete understanding and representations of the driving mechanisms of dust emission, transport and deposition, dust particle size and shape, as well as model structural differences. It also remains a challenge for climate models to accurately simulate the meteorological processes that play critical roles in dust processes. Yet, these uncertainties tend to amplify as models become more complex (Kok et al., 2017; Ryder et al., 2019; Adebiyi and Kok, 2020; di Biagio et al., 2020; Kramer et al., 2020; Li et al., 2021; Huang et al., 2021). 
Uncertainties in the simulation of dust have important implications for interpreting the model-simulated global radiation

40 budgets, and many processes that are influenced by dust (e.g., clouds). Also, in the context of global efforts to mitigate anthropogenic aerosol and precursor emissions, natural aerosols like dust will potentially play a greater role in shaping future climate variability as they become a larger fraction of the total aerosol burden. Therefore, it is crucial to understand the performance of dust simulations in the latest generation climate models.

The first multi-model and multi-parameter evaluation of dust simulations was carried out within 15 models participating in

45 Phase I of the Aerosol Comparison between Observations and Models (AeroCom I) (Huneeus et al., 2011). These models were able to reproduce vertically integrated parameters such as dust aerosol optical depth (DOD) within a factor of two, and the dust deposition and surface concentration within a factor of 10. Kim et al. (2014, 2019) evaluated AeroCom phase II modelsimulated DOD over North Africa and East Asia against multiple observational datasets, and found these models significantly underestimated dust transport to adjacent oceans. The latest AeroCom phase III models are reported to have better resolved

50 dust particle size distributions compared to those in phase I and II (Gliß et al., 2021). However, dust particles are still too fine compared to the Aerosol Robotic Network retrievals (AERONET) (Holben et al., 1998). Also, large diversities were found across different models in the simulations of dust emission, burden and lifetime. This leads to diversities in dust spatial distributions and transport to the oceans. These have implications for interpreting the diversities in model-simulated aerosol optical properties and aerosol-radiation-cloud interactions.

55 Several studies have examined the performances of the CMIP5 models in dust simulations at both regional and global scales. For example, Evan et al. (2014) found that the African dust emissions and burdens were systematically underestimated in 23 CMIP5 models, while their year-to-year changes were poorly constrained compared to observations. Similarly, it was shown that CMIP5 models significantly underestimated dust transport to the Indian subcontinent because of biases in the modelsimulated 850-hPa winds (Sanap et al., 2014). Wu et al. (2019) found large discrepancies between satellite-observed and

60 CMIP5 models' simulated decadal variabilities of dust emissions over East Asia, and questioned the implications for longterm variations in dust-related processes. Pu and Ginoux (2018) compared seven CMIP5 models' simulated DOD to the Moderate Resolution Imaging Spectroradiometer (MODIS) Deep Blue aerosol product. They found that the multi-model mean was better than most individual models in capturing the climatology and seasonal cycles of DOD over most dust source regions, but that it still underestimated the mean value and the amplitude of the seasonal cycle. This is consistent with the representation

65 of wind/precipitation processes in the models (i.e., the multi-model mean outperforms individual models) (Sperber et al., 2013). Almost all the seven models failed to capture the DOD interannual variations. Dust cycles in the CMIP5 models were further evaluated by Wu et al., (2020a) against the MERRA2 aerosol reanalysis and station observations. They found that CMIP5 models, compared to the AeroCom II models, featured amplified uncertainties, and attributed this to increases in model complexities such as the coupling between dust emissions and dynamic vegetation. In short, although CMIP5 models were

70 able to simulate some aspects of dust distribution and seasonal cycles well, their ability to represent certain features was still limited, and inter-model variability was too large to provide useful constraints on dust interactions with the climate system. The CMIP6 models (Eyring et al., 2016) represent significant advances compared to the CMIP5 models in many ways. For example, the inclusion of additional Earth system components and processes, such as dynamic vegetation, in a greater proportion of models. For dust aerosols, given the large uncertainties in previous generations of climate models discussed

75 above, it is important to evaluate the performance of the CMIP6 models. Especially, how well do these models simulate dust processes compared to each other and compared to observations and previous generations of models. Such understanding would serve as a benchmark for the dust-modelling community to interpret a variety of processes related to dust in climate models, while also help climate model centres to develop their models into the next phase, and help target future observations directed towards constraining model processes.

80 Here we provide the first comprehensive intercomparison and evaluation of the CMIP6 models in dust simulations at the global scale while focusing on a few key dust source regions. We examine 16 CMIP6 models that performed the Atmospheric Model 

model-simulated dust emission, deposition, burden, lifetime, and DOD to multiple reanalyses and observational datasets. We also examine the driving processes of dust emissions using a regression technique. This paper is organised as follows. Section 2 briefly introduces the 16 models and simulations we examine in this work, as well as the reanalysis and observational datasets, and statistical analyses. Results are presented in Section 3, followed by a summary of key findings and discussions in Section 4.

\section{Data and methods}

\subsection{CMIP6 AMIP models and simulations}

90 We examine dust in 16 climate and Earth System models (hereafter ESMs; Table 1) participating in the CMIP6 AMIP (Eyring et al., 2016). These models were selected based on solely the criterion that at least the monthly mean DOD field was available at the time of writing. AMIP is one of the four CMIP6 baseline Evaluation and Characterization of Klima (DECK) experiments. In AMIP, sea surface temperature and sea ice are prescribed from observations, so that the atmospheric and land components within each model can be evaluated under the constraint of observed ocean conditions. Subcomponent models in each ESM,

95 as well as external forcings such as greenhouse gas concentrations and land use, are identical to those in the CMIP6 historical simulations. All models analysed here cover at least the period 1979-2014. We focus on the present-day (2005-2014) period for model evaluation, guided by the availability of observational (i.e., satellite) and reanalysis datasets (See Sections 2.2 and 2.3). In Section 3.2, we also use the 1985-2014 data to ensure the robustness of the regression analysis for determining dust emission drivers.

100 Unlike previous generation CMIP models, dust emissions in almost all the 16 CMIP6 models (except INM-CM4-8) are calculated online and resolved into different size bins (see Table 1). However, dust particle size range represented differ significantly between models, with the use of bin-based and model schemes, and maximum diameter (bin-based) ranging from 0.01 up to $63 \mu \mathrm{m}$ in diameter. Depending on the model, dust emissions are calculated based on factors such as surface winds, land surface properties, and vegetation. Dust particles interact with clouds by serving as cloud condensation nuclei in most of the 16 models; however, only two models (MRI-ESM2-0 and NorESM2-LM) have realised dust particles as ice nuclei.

For models that have more than one ensemble member, we average these members to produce a model ensemble mean unless otherwise stated. The model ensemble mean is used to represent each individual model, and is interpolated to the UKESM-0LL model grid when calculating the multi-model ensemble mean (MEM). The UKESM-0-LL model grid was chosen as it is the intermediate horizontal resolution between the highest and the lowest ones. We also calculate the $10^{\text {th }}-90^{\text {th }}$ percentiles of

110 the multi-model spreads when producing zonal and meridional mean profiles, as well as the seasonal cycles of regional mean dust emissions and DOD. The climatological means were calculated as averages of the 2005-2014 annual means from each model ensemble mean.

\subsection{Satellite aerosol optical depth products}

Satellite observations are one of the most reliable tools for constraining and evaluating ESMs at the global scale (Flato et al.,

115 2013). Here we use satellite AOD and DOD retrievals at $550 \mathrm{~nm}$ to evaluate the performances of the CMIP6 AMIP models over the period 2005-2014.

There are currently several satellite DOD products developed using the MODIS and/or the Advanced Very High Resolution Radiometer (AVHRR) observations (Ginoux et al., 2012; Pu and Ginoux, 2018; Voss and Evan, 2020), and each has its own limitations and advantages. Here we use the ModIs Dust AeroSol (MIDAS) dataset (Gkikas et al., 2021) that provides globalscale land and ocean daily DOD with fine spatial resolution $\left(0.1^{\circ} \times 0.1^{\circ}\right)$ for the period 2003-2016. MIDAS was calculated 
using quality filtered MODIS-Aqua AOD retrievals along with DOD-to-AOD ratios provided by the Modern-Era Retrospective analysis for Research and Applications version 2 reanalysis (MERRA2). The MIDAS dataset was validated against the AERONET and the LIdar climatology of vertical Aerosol Structure for space-based lidar simulation (LIVAS) DOD products, and was demonstrated as suitable for DOD climatology study and model evaluation (Gkikas et al., 2021).

We also use the 12-satellite merged AOD product developed by Sogacheva et al., (2020) at the Finnish Meteorological Institute (FMI AOD thereafter). FMI AOD provides monthly data for the period 1995-2017 at a $1^{\circ} \mathrm{x} 1^{\circ}$ horizontal resolution. It has better spatial and temporal coverage than any individual satellite AOD products, while the quality of the merged product is at least as good as that of individual products.

\subsection{CAMS and MERRA2 reanalyses}

The Copernicus Atmosphere Monitoring Service (CAMS; Inness et al. (2019)) reanalysis represents the latest global reanalysis dataset of the atmospheric composition produced by the European Centre for Medium-Range Weather Forecasts (ECMWF). It assimilates satellite retrievals of many atmospheric constituents including $\mathrm{CO}, \mathrm{NO}_{2}, \mathrm{O}_{3}$, as well as AOD from MODIS Terra and Aqua and AATSR (Advanced Along-Track Scanning Radiometer) Envisat, using the ECMWF's Integrated Forecasting System. The CAMS reanalysis is available from 2003 onward at a horizontal resolution of $\sim 80 \mathrm{~km}$. Dust emission is calculated based on Ginoux et al., (2001), and is resolved in three size bins with diameter bounds at 0.06,1.1, 1.8 and $40 \mu \mathrm{m}$, respectively (Table 1). Monthly mean AOD and DOD are available, while dust cycle fluxes including dust emission and deposition are provided at 3-hr intervals which were processed into monthly means. We also use the 2005-2014 monthly mean bare soil fraction and leaf area index from CAMS, as well as soil moisture, surface winds, and precipitation from ECMWF Reanalysis version 5 (ERA5), to investigate the drivers of dust emissions (See Section 2.4).

140 In addition to CAMS, we also use the MERRA2 reanalysis which was produced using the Goddard Earth Observing System (GEOS-5; Molod et al. (2015)) with a 3D variational data assimilation system (3D-Var) that assimilates a wide range of observational datasets (Gelaro et al., 2017). For AOD, MERRA2 assimilates data from AVHRR, MODIS, the Multi-angle Imaging SpectroRadiometer (MISR), and AERONET. Dust emission is simulated based on Ginoux et al. (2001), and is resolved in five size bins with diameter bounds at 0.2, 2.0, 3.6, 6.0, 12.0 and $20.0 \mu \mathrm{m}$ respectively (Table 1). In addition to its AOD and DOD products, MERRA2 also provides dust emission and deposition fluxes at $0.1^{\circ}$ horizontal resolution from 1980 onward, making it a valuable tool for evaluating dust processes in climate models. We use the MERRA2 monthly mean AOD and DOD, as well as dust cycle fluxes (emission, dry deposition and wet deposition, and burden) over the period 2005-2014. Note we were not able to investigate the drivers of dust emissions using MERRA2, because bare soil fraction data is not provided.

\subsection{Multiple linear regression}

To investigate factors that drive dust emissions, we performed a multiple linear regression (ordinary least square) on standardised dust emissions and their drivers (Seabold and Perktold, 2010). We started the regression with five dust emission drivers: bare soil fraction, leaf area index, precipitation, soil moisture, and surface winds. However, we made leaf area index and soil moisture redundant after the variance inflation factor analysis which indicates these two variables bear similar information to others included in the regression (not shown). We regressed gridcell dust emission to bare soil fraction, precipitation, and surface winds using standardised monthly mean data over the period 1985-2014 for each individual model and over 2005-2014 for CAMS. Note that due to data availability, we were only able to do this with 10 of the 16 CMIP6 models and CAMS (see Section 3.1.3).

We take the absolute value of the three regression coefficients as an indication of the importance of each in driving dust emission, and measure their relative importance by normalising each coefficient against the sum of the three. Bootstrap 

at regional scales in different seasons, we repeat the regression for each individual calendar month using standardised regionaland monthly-mean data calculated from each of the 10-individual models (not shown) as well as the model ensemble mean.

\section{Results}

\subsection{Dust emission}

We start with the climatology and global budget (Figures 1, 2 and Table 2) of dust emissions. We then show the seasonal cycles (Figure 3) of dust emissions over the eight major source regions (See Figure S1 for region definitions). Next, we look at the drivers of dust emissions in each individual model and CAMS reanalysis at the global scale (Figure 4), and demonstrate the relative importance of each driver in different seasons at regional scales (Figure 5). We focus primarily on the differences between individual models, while comparing them to the CAMS and MERRA2 reanalyses. We also compare and discuss our results with previous generation ESMs, with CMIP5 (Evan et al., 2014; Wu et al., 2020a, b) and AeroCom III models (Gliß et al., 2021) in particular.

\subsubsection{Climatology}

Figure 1 shows the 2005-2014 global- and annual-mean climatology of dust emissions in each individual model; the MEM is shown in Figure 2a and is compared to CAMS (Figure 2b) and MERRA2 (Figure 2c). Models generally capture the dust emission hotspots, namely the so-called 'dust belt' (Ginoux et al., 2012) that extends from North Africa, the Middle East, Central Asia, South Asia to East Asia. However, similar to CMIP5 models (Wu et al., 2020a), there are considerable differences between models in other source regions such as North and South America and Australia. Models show significant differences in the intensity and spatial heterogeneity of dust emissions, reflecting the structural differences in dust emission schemes implemented in different models. Particularly, CESM2 models (Figures 1a-d) and NorESM2-LM (Figure 1o) put dust emissions in a few gridcells, whereas dust emissions in HadGEM-GC31-LL (Figure 1i), INM-CM4-8 (Figure 1j) and INMCM5-0 (Figure 1k) models have relatively homogeneous spatial patterns and significantly larger source areas (also see Figure 2e). The spatial pattern and magnitudes of dust emission in the MEM are in broad agreement with CAMS and MERRA2. Pronounced differences are however found outside dust emission hotspots. This is because a few models (HadGEM-GC31-

185 LL, INM-CM4-8, and INM-CM5-0) emit dust over these regions that are rarely deemed as potential dust sources (Ginoux et al., 2012).

The CMIP6 models estimate that between 1.4 (INM-CM4-8) and 7.6 (MIROC-ES2L) Pg dust is emitted into the atmosphere annually, producing a MEM estimate of around 3.5 $\mathrm{Pg} \mathrm{yr}^{-1}$. The CMIP6 model range is just as large as the CMIP5 models (0.7-8.2 $\mathrm{Pg} \mathrm{yr}^{-1}$; Wu et al., (2020a)), and is much larger than the AeroCom phase III models (0.8-5.7 $\left.\mathrm{Pg} \mathrm{yr}^{-1}\right)$ and the recent observationally-constrained estimates of $\sim 5 \mathrm{Pg} \mathrm{yr}^{-1}$ (Kok et al., 2021). 12 of the 16 models simulate significantly more dust emissions than CAMS and MERRA2 reanalyses ( 1.6 $\mathrm{Pg} \mathrm{yr}^{-1}$; Figure 2d), making the MEM more than two times larger than

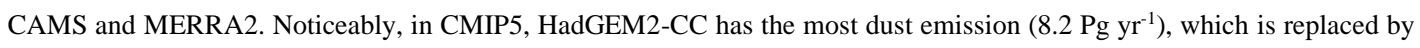
UKESM1-0-LL (7.5 $\mathrm{Pg} \mathrm{yr}^{-1}$ ) and MIROC-ES2L (7.6 $\mathrm{Pg} \mathrm{yr}^{-1}$ ) in CMIP6, while HadGEM-GC31-LL (3.3 Pg $\left.\mathrm{yr}^{-1}\right)$ lies very close to the CMIP6 MEM estimate. The 2-fold difference in dust emissions between UKESM1-0-LL and HadGEM-GC31-LL is attributable to the additional Earth system interactions such as the dynamic vegetation included in UKESM1-0-LL (Mulcahy et al., 2020). This demonstrates the strong impact of model complexities on simulated dust emissions.

North Africa contributes the most (57 (28-69) \%) to global dust emissions in CMIP6 models (Figure 2d), generally agreeing with CAMS (46\%) and MERRA2 (60\%). This is followed by the Middle East (17 (11-25) \%) and North China (9 (2-16) \%). It is worth noting that the contribution of North Africa to global dust emission may be overestimated, while those of the Middle 
200 East and North China may be underestimated (Kok et al., 2021). These three regions make up more than $80 \%$ of global dust emissions, while models disagree fundamentally about the relative contributions of other source regions. Particularly, South Asian dust emission is only important in UKESM1-0-LL, contrasting to the very limited dust emissions in all other models in this region including HadGEM-GC31-LL.

CMIP6 models also feature diversities in the global surface area of dust emissions (Figure 2e), with the smallest area (around

$2052.5 \%$ of the global surface area) found in the CESM2 family models and NorESM2-LM, and the largest in INM-CM4-8 (15.0\%). The MEM estimate (11.5\%) is almost two times larger than that of MERRA2 (6.6\%) and CAMS (5.6\%). The range of the CMIP6 model estimates (2.5-15.0\%) is almost as large as that of the CMIP5 models (2.9-19\%; Wu et al., (2020a)) as reported by Wu et. al., (2020a). Note that the models that have the highest dust emissions do not necessarily have the largest emission areas, and vice versa. This again suggests the large diversities in dust emission intensities in different models.

210 3.1.2 Seasonal cycles

Figure 3 shows the normalised seasonal cycles of dust emissions over the eight source regions; the absolute seasonal cycle profiles can be found in Figure S2. The MEM agrees well with CAMS and MERRA2 in reproducing the patterns of the seasonal cycles. However, noticeable discrepancies are found between individual models and reanalysis over a few key regions including North China (Figure 3d), North America (Figure 3g) and South America (Figure 3h). Dust emission peak seasons in

215 these regions have large diversities between models. Two models behave very differently from others. First, the CanESM5 model simulates very different dust emission peak seasons over the Middle East (Figure 3c), North China, South Asia and North America. Second, MIROC-ES2L is the only model that simulates a summer peak while all others show a spring peak over North Africa (Figure 3a).

The seasonal cycles feature a double peak over North China and North America in a few models (CanESM5, MIROC-ES2L,

220 INM-CM4-8, INM-CM5-0, MRI-ESM2-0), while the reanalysis datasets and most other models and reanalysis datasets present a single spring emission peak. The underlying mechanisms that drive these double peaks differ between these two regions. The models that simulate a secondary autumn emission peak in North China are found to have too strong surface winds in autumn and winter. In comparison, a deficit in autumn precipitation explains the secondary emission peak in North America (Figures not shown).

225 The magnitude of the seasonal cycles in MEM and most individual models are much larger (up to 10 times) than those in CAMS and MERRA2 (Figure S2) which lie very close to the lower bounds of the AMIP multi-model spreads. This is consistent with our finding above that the CMIP6 models have considerably more dust emissions than reanalysis (Section 3.3.1). Particularly, UKESM1-0-LL may overestimate dust emissions in South Asia and Australia (Figures S2e, f). By contrast, the INM-CM4-8 and INM-CM5-0 models may have too little dust emissions over North Africa (Figure S2a).

230 In short, the seasonal cycles of dust emissions over major source regions are well reproduced by the MEM and most individual models, but a few models behave very differently to others over North China, North America and South America.

\subsubsection{Drivers}

Figure 4 shows the dominant driver of dust emissions at each gridcell in the 10 CMIP6 models and the CAMS reanalysis, based on the methodology set out in Section 2.4. Surface wind speed is shown as the dominant driver of dust emissions in all the models and CAMS. Precipitation only dominates dust emissions in the INM-CM4-8 and INM-CM5-0 models over a few regions (Figure 4i, j). Our finding is consistent with Pu and Ginoux (2018) who show that surface winds and precipitation are two of the most important factors determining seasonal DOD variations in the CMIP5 models.

We further examine the relative importance of each individual driver and their seasonal variations over the eight major dust source regions in the MEM (Figure 5). The dominant role of surface winds in driving dust emission can be seen over North 
240 Africa (Figure 5a), the Middle East (Figure 5c) and North China (Figure 5d) throughout the year, whilst surface bareness also plays an important role in other regions. Precipitation (influencing soil moisture) is shown to influence dust emission in North Africa, with the largest impact found in summer. Similarly, precipitation plays an important role in South Asian dust emission around the post-monsoon season in October (Figure 5e). In other regions, precipitation shows a relatively minor contribution. Overall, we found that surface wind and bareness are the first two most important factors in driving dust emissions in CMIP6 models and CAMS. We hence speculate that future changes to dust emissions may be most sensitive to changes in the surface wind related to circulation changes in combination with vegetation changes, rather than the frequency or severity of droughts, though the latter may indirectly influence future dust emissions via vegetation changes. However, it should be noted that surface bareness was found to play the most important role in controlling DOD over many dusty regions in observations $(\mathrm{Pu}$ and Ginoux, 2018). The fact that models do not simulate significant trends in surface bareness over time explains why surface bareness plays a secondary role compared to surface winds in driving dust emissions in models, since the required criteria for dust emission are already satisfied.

\subsection{Dust loading, deposition and lifetime}

This section examines atmospheric dust mass loading (Figure 6) and deposition fluxes (Figure 7) which in combination determine the atmospheric dust lifetime (Figure 8). The global budgets of these fluxes in each model are summarised in Table

2, and their global climatologies are included in Supplementary Figures S3-S5.

The spatial pattern of the dust mass loading climatology in MEM (Figure 6a) shows good agreement with CAMS (Figure 6b) and MERRA2 (Figure 6c), while the magnitudes are slightly larger. The global total atmospheric dust burden in MEM (25 Tg) is comparable to that of MERRA2 (23 Tg), and is two times larger than that of CAMS (12 Tg). Most models' simulated global total dust burden lies well around the MEM and reanalysis estimates (Figure 6d). However, the CESM2-WACCM-FV2 model simulates significantly more dust in the atmosphere ( $74 \mathrm{Tg}$ ). The range of global total dust burden in CMIP6 with the CESM2WACCM-FV2 model excluded is 9-28 Tg. This is larger than that of the AeroCom III models (6-22 Tg; Gliß et al., (2021)), but smaller than the CMIP5 models (3-42 Tg; Wu et al., (2020a)).

We calculated the meridional mean profiles of dust mass loading and DOD (Figures $6 \mathrm{e}, \mathrm{f}$ ) to examine the gradients associated with dust transport from land to the adjacent oceans from the two largest source regions: North Africa and North China. Note here we show the DOD profiles because more model and observational data are available for comparison, but similar conclusions can be drawn if one looks at the mass loading profiles (Figure S6). Most models, and particularly the MEM, reproduce well the gradients compared to both reanalysis and satellite observations. However, the magnitudes of the profiles are too low in INM-CM5-0 and UKESM1-0-LL, but too high in CESM2-WACCM-FV2 over the Africa-Atlantic region (Figure 6e). By contrast, many models (CNRM-ESM2-1, HadGEM3-GC31-LL, MIROC-ES2L, MRI-ESM2-0, INM-CM4-8,

270 INM-CM5-0, and UKESM1-0-LL) do not produce ample gradients over the Asia-Pacific region (Figure 5f). Figure 7 shows the climatology of the total (dry + wet) dust deposition flux and the percentage of wet deposition. Globally, CMIP6 models estimate that 3.5 (1.3-7.4) Pg dust is removed from the atmosphere annually, which is consistent with the MERRA2 (1.6 $\left.\mathrm{Pg} \mathrm{yr}^{-1}\right)$ and CAMS (6.6 $\mathrm{Pg} \mathrm{yr}^{-1}$ ) estimates. As summarised in Table 2, dust is predominantly removed by dry deposition (60-86\%) in most models, agreeing with CAMS (69\%) and MERRA2 (70\%), yet the CESM2 models show that $\sim 74 \%$ of the total dust removal is via wet processes. Dust removal over the oceans is controlled by wet deposition, while dry processes dominate over lands (Figures $7 \mathrm{~b}, \mathrm{~d}, \mathrm{f}$ ).

Figure 8 summarises the differences in global dust burden, deposition fluxes and lifetime (global dust burden divided by total deposition fluxes) between models and analysis datasets. Dust lifetime in CMIP6 models ranges by a factor of 4 from around 1.8 days to 6.8 days; with a MEM estimate of 4.3 days. The range is larger than the CMIP5 models (1.3-4.4 days; Wu et al., (2020a)), and is just as large as the AeroCom III models (1.4-7.0 days; Gliß et al., (2021)). MERRA2 (5.2 days) lies within 
the range of the CMIP6 model estimates. In comparison, CAMS is likely to underestimate dust lifetime (0.6 days) because of high deposition rates which lead to less dust in the atmosphere (see above). We found a linear relationship between dust lifetime and the ratio of global dry-to-total depositions across different models (Figure 8b). This suggests that dry processes control dust lifetime, which is further demonstrated by the strong (weak) linear correlation between dust lifetime and dry (wet) deposition across different datasets (Figures $8 \mathrm{c}, \mathrm{d}$ ). That is, the less the dry processes, the longer dust resides in the atmosphere before being finally removed by the relatively infrequent wet depositions events, occurring mostly further from dust sources compared to dry deposition.

\subsection{AOD and DOD}

In this section, we turn to DOD that is associated with the above-presented dust processes. In addition to evaluating CMIP6 model-simulated DOD, we also examine whether models' performances in simulating the optical depth of dust differ to those of other aerosol species. We first show differences in model-simulated AOD (Figure 9) and DOD (Figures 10-11) and then examine where such differences come from (Figure 12). Finally, we examine the seasonal cycles of DOD, whilst comparing them with the seasonal cycles of dust emissions, over the eight major dust source regions.

Figure 9 shows an intercomparison of the AOD climatology between the MEM and those from satellite and reanalyses. The

295 AOD climatology in each individual model is included in Figure S7. The MEM, and most individual models, reproduces the AOD climatology well. However, a few models (GISS-E2-1-G, GISS-E2-2-G, INM-CM4-8, INM-CM5-0) struggle to capture the AOD spatial pattern: the spatial correlation $\left(\mathrm{R}^{2}\right)$ between these models and satellite and reanalysis datasets are less than 0.2 (Figure 9h). By contrast, the HadGEM3-GC31-LL, MIROC-ES2L, MRI-ESM2-0, and UKESM1-0-LL models' simulated AOD have even greater spatial correlations to satellite and reanalysis datasets compared to the MEM. Compared to AOD, the

300 MEM DOD climatology (Figures 11a) has slightly greater spatial correlations with satellite $\left(R^{2}=0.76\right)$ and reanalyses $\left(R^{2}=0.85\right.$ and 0.86). However, the models that simulate the spatial pattern of DOD well do not necessarily perform well in simulating AOD (comparing Figure $9 \mathrm{~h}$ to Figure 11h). For example, the two GISS models (denoted by letters $\mathrm{g}$ and h, also see Figures $\mathrm{S} 7 \mathrm{~g}, \mathrm{~h}$ ) are top-ranked in capturing the spatial pattern of DOD (Figure 11h), but are lowest-ranked in simulating the spatial pattern of AOD (Figure 9h). This highlights the inconsistent behaviour of CMIP6 models in simulating the optical depth of different aerosol species. More importantly, careful comparisons between as Figures 9e-g and Figures 11e-g indicate that the magnitudes of DOD have larger biases than AOD.

CMIP6 model-simulated global mean DOD varies by a factor of 7 from 0.011 to 0.073 , with the MEM estimate of 0.029 which is consistent with the MIDAS satellite (0.033) and MERRA2 (0.030) datasets but is $~ 1.5$ times that of CAMS (0.019). There are however significant biases in the MEM-simulated DOD magnitudes at regional scales. For example, models tend to

310 overestimate DOD, which can be seen over the Sahara and the Chinese deserts in the MEM and in most models. More specifically, the AMIP MEM estimate of the regional mean DOD in North Africa (0.278) is 1.2-1.7 times larger than those of satellite (0.228) and reanalysis datasets (0.165 in CAMS and 0.238 in MERRA2). Similarly, the MEM overestimate North China mean DOD (0.142) by 1.2-1.5 times compared to satellite (0.097) and reanalyses (0.118 in CAMS and 0.099 in MERRA2). Such overestimates can reach up to 4-5 times in a few models such as CESM2-WACCM-FV2 (Figure 10d) and

315 MIROC-ES2L (Figure 10m). We note however that previous studies using CMIP5 and AeroCom III models concluded that DOD in these regions were well captured (Pu and Ginoux, 2018; Gliß et al., 2021). Finally, it is important to point out that none of the 16 models, nor the reanalyses, are able to capture the dust transportation and accumulation along the southern Himalayas as shown by satellite data (Figure 11a). Also, none of the AMIP models captures the regional DOD variability over the Middle East, Central Asia, the Chinese desert and eastern China (Figure 11a).

320 We showed above the biases in model-simulated DOD magnitudes. Here we further investigate such biases by looking at the DOD probability density distributions of the models in comparison to satellite and reanalyses, as a function of the difference 
in the magnitude of the DOD. This gives an insight into how well the models represent weaker vs heavier dust events. Model gridcell DOD values are grouped into three categories $(\leq 0.1,0.1-0.4$ and $>0.4)$ to calculate the normalised probability density function independently (Figure 12a-c). Almost all models and the MEM underestimate small ( $\leq 0.1)$ DOD values (Figure 12a) while significantly overestimating large (>0.4) DOD values (Figure 12c). By contrast, the moderate DOD values (Figure 12b) are relatively well reproduced. We note that models overestimate small DOD values compared to CAMS, while the CAMS DOD is low compared to the other datasets (see above). To further understand where the biases in models' simulated DOD come from, we examine the global zonal mean DOD profile and the distribution of regional mean DOD over the eight major dust source regions in Figure 12d. The overestimates (black crosses), compared to both satellite and reanalysis datasets (blue/green/purple crosses), can be seen over North Africa, North China, South Africa and Australia. Meanwhile, DOD is underestimated over South Asia, which again implies that models fail to capture the dust accumulations in the Indian subcontinent.

The model-simulated seasonal cycles of DOD (Figures 13 and S8) are in broad agreement with reanalysis and satellite observations. However, noticeable discrepancies are again found in South Africa (Figure 13b), North China (Figure 13d), North America (Figure 13g), and South America (Figure 13h) where there are also large inter-model discrepancies in the simulated seasonal cycles of dust emission. By contrast, the Middle East (Figure 13c) and South Asia (Figure 13e) show good agreement between satellite-observed and model-simulated DOD seasonal cycles. Finally, it is interesting to note that the seasonal cycle of DOD over North Africa peaks slightly later (early summer) than dust emission (early spring). This may indicate the importance of dust transport in influencing dust optical depth and its seasonal cycles. Also, there seems to be a split into 2 groups of models between the ones that sustain DOD over the summer versus the ones which drop off in June/July (Figure 13a). Overall, similar to dust emissions, the seasonal cycles of DOD are well reproduced by most models, and the MEM does a good job in capturing DOD seasonal cycles in most regions. However, a few models still struggle to capture the seasonal cycles over North China, North America and South America.

\section{Conclusions and discussions}

345 In this study, we examine dust aerosols in 16 state-of-the-art Earth system models participating in the CMIP6 AMIP. We evaluated models' present-day (2005-2014) dust aerosol processes (emission, deposition, burden, lifetime), as well as dust aerosol optical depth (DOD), against several global reanalysis and observational datasets. Note that we did not evaluate the models against ground-based measurements but instead perform a large-scale analysis focussing on the more spatio-temporally available fields from reanalyses that are in good agreement with ground-based observations where they exist (Wu et al., 2020a, b). We presented our findings in the context of CMIP5 and AeroCom III models. Out key findings are:

- The CMIP6 models generally capture the spatial patterns of global dust emission, mass loading, and removal processes. However, large uncertainties and inter-model diversities (a factor of 4-5) are found in all these fields.

- The global dust emission is predominantly driven by surface winds (as opposed to bare soil fraction and precipitation) in models and the CAMS reanalysis.

- Most models, and particularly the MEM, capture dust seasonal cycles over major source regions. However, the seasonal cycles are poorly constrained over North China, North America and South America.

- CMIP6 models simulate large diversities in global mean DOD that range by a factor of 7. The MEM estimate however is consistent with both satellite and reanalyses.

- Almost all CMIP6 models underestimate small DOD values but significantly overestimate large DOD values compared to satellite and reanalyses; the overestimates are found mainly over the dustiest regions such as North Africa (1.2-1.7 times in MEM) and North China (1.2-1.5 times in MEM). 
- The CMIP6 models consistently fail to capture certain key features of regional dust distributions. For example, dust accumulations along the southern edge of the Himalayas, and regional DOD variability over East and Central Asia and the Middle East.

Additionally, it is worth summarising the following quantitative findings:

- Around 3.5 (1.4-7.6) Pg of dust are emitted annually in the CMIP6 models, the MEM estimate is double the amount in the MERRA2 and CAMS reanalyses. A similar overestimate was highlighted in previous studies for CMIP5. Also, there are large diversities in the extent (2.5-15.0\% of global surfaces) and intensity of dust emission between models.

- North Africa, the Middle East and North China combined make up over $80 \%$ of global total dust emissions. However, models disagree considerably about the contributions from other dust source regions.

- There are large uncertainties in the global total dust burden $(9-74 \mathrm{Tg})$ in the atmosphere; the estimated range is much larger than that in CMIP5 (3-42 Tg) and AeroCom III (6-22 Tg) models.

- The global dust removal ( 3.5 (1.3-7.4) $\left.\mathrm{Pg}^{\mathrm{r}-1}\right)$ is dominated by dry deposition processes (60-86\%) which are found to control global dust lifetime that varies by a factor of 4 from 1.8 to 6.8 days in CMIP6 models.

Overall CMIP6 models generally reproduce global dust processes, and the MEM performs better than most individual models. Nevertheless, large model uncertainties and diversities still exist. This may be associated with increases in model complexities, as demonstrated by the difference between HadGEM-GC31-LL and UKESM-0-LL (Mulcahy et al., 2020). Models still suffer from deficiencies in simulating the dust seasonal cycles, distribution and optical depth over key source regions. Also, models struggle to agree about the seasonal cycles of dust over a few key source regions such as North China, and South and North America. The North China region appears to be particularly challenging for models, which overestimate DOD and frequently represent the seasonal cycle incorrectly in this region.

The variability across CMIP6 models is generally larger than those in the CMIP5 and AeroCom phase III models. Despite the fact these are different subsets of models with some overlaps, it may indicate that dust processes are becoming more uncertain as models become more sophisticated (Wu et al., 2018). Further, there are inconsistent biases along the lifecycle of dust in different models. This indicates the challenges in simulating the links between dust emission, mass loading, AOD (relating to size, optical properties), and deposition in CMIP6 models. These challenges come from various sources such as difficulties in accurately simulating dust-land-vegetation-climate interactions. We therefore recommend more detailed output relating to the dust cycle in future model intercomparison projects. This will enable us to better constrain global dust cycles, as well as the potential identification of observationally-constrained links between dust cycles and optical properties. It should be noted that

we examined the AMIP model simulations. It is therefore reasonable to speculate even greater model uncertainties and deficiencies exist in fully-coupled models due to the couplings between dust and many other components of the Earth system. There are large diversities in CMIP6 models' simulated spatial patterns and magnitudes of DOD. This is particularly true over the dustiest regions such as North Africa, North China and the Middle East. Almost all models significantly overestimate DOD values over these regions. It is difficult to investigate the reasons behind this overestimate using the CMIP6 experiments because many dust variables are not available. We suggest that sensitivity experiments may be a better approach to understand this overestimate in future work. One of the outstanding questions to answer in the future centres around the dust particle size distributions over these dust source regions. For example, can model biases in dust particle size distributions explain the overestimation of large DOD values over dust source regions?

It is worthwhile stressing that both the CMIP6 models and the reanalysis datasets fail to capture the spatial patterns of dust over the Middle East, East China and South Asia. Given that the meteorological drivers (i.e., winds and precipitation) of dust emissions over these regions are largely influenced by large-scale monsoonal circulations, the biases in dust simulations may be ascribed to the poorly represented monsoon systems in CMIP6 models (Wu et al., 2018; Wilcox et al., 2020; Jin et al., 2021). In the meantime, these biases may also cast doubt on model-simulated regional- to global-scale atmospheric circulations and climate states through dust-radiation-climate interactions. For example, the location of the Pacific Interhemispheric 
405 Convergence Zone (ITCZ) which is found to be linearly correlated to dust mass loadings over these regions (Evans et al., 2020).

In summary, the CMIP6 models, and particularly the MEM, generally capture key features of global dust processes. For example, the global dust emission regions, global DOD distribution, and dust seasonal cycles over a few key source regions. However, dust aerosols in CMIP6 models still present large uncertainties, and the uncertainty ranges tend to expand compared

410 to previous generations climate models. The dust processes have inconsistent biases in different models, adding the urgency to better constrain the whole life cycle of dust and the links between different dust processes in climate models. This also provides caveats in interpreting the impacts of dust on other Earth system processes such as the radiation budget, clouds, precipitation and atmospheric circulations. 


\section{Code and data availability}

415 This work uses simulations from 16 models participating in the AMIP project as part of the Coupled Model Intercomparison Project (Phase 6; https://www.wcrp-climate.org/wgcm-cmip, World Climate Research Program, 2020); model-specific information can be found through references listed in Table 1. Model outputs are available on the Earth System Grid Federation (ESGF) website (https://esgf-data.dkrz.de/search/cmip6-dkrz/, Earth System Grid Federation, 2020). Satellite and reanalyses data used in this work are all cited. The analysis was carried out using Bash and Python programming languages.

\section{Author contribution}

All authors designed the study. AZ performed the analysis and wrote the first draft, and all authors contributed to the writing of the paper.

\section{Competing interests}

The authors declare that they have no conflict of interest.

\section{Acknowledgements}

We acknowledge the World Climate Research Programme, which, through its Working Group on Coupled Modelling, coordinated and promoted CMIP6. We thank the climate modelling groups for producing and making available their model output, the Earth System Grid Federation (ESGF) for archiving the data and providing access, and the multiple funding agencies who support CMIP6 and ESGF. We thank Ben Johns, Matthew Mizielinkski, Mohit Dalvi and Jeremy Walton from

430 the UK Met Office for providing model data. We also thank Michela Giusti and Kevin Marsh from the ECMWF for helping to prepare the CAMS dust emission and deposition data.

\section{Financial support}

This work and its contributors AZ, CLR, and LJW were supported by the UK-China Research and Innovation Partnership Fund through the Met Office Climate Science for Service Partnership (CSSP) China as part of the Newton Fund. CLR was 435 supported by a UK Natural Environment Research Council (NERC) independent research fellowship grant (grant no. NE/M018288/1). 


\section{References}

Adebiyi, A. A. and Kok, J. F.: Climate models miss most of the coarse dust in the atmosphere, Sci. Adv., 6, eaaz9507, https://doi.org/10.1126/sciadv.aaz9507, 2020.

440 Bauer, S. E., Tsigaridis, K., Faluvegi, G., Kelley, M., Lo, K. K., Miller, R. L., Nazarenko, L., Schmidt, G. A., and Wu, J.: Historical (1850-2014) Aerosol Evolution and Role on Climate Forcing Using the GISS ModelE2.1 Contribution to CMIP6, 12, e2019MS001978, https://doi.org/10.1029/2019MS001978, 2020.

Biagio, C. D., Balkanski, Y., Albani, S., Boucher, O., and Formenti, P.: Direct Radiative Effect by Mineral Dust Aerosols Constrained by New Microphysical and Spectral Optical Data, 47, e2019GL086186, https://doi.org/10.1029/2019GL086186, 2020.

Boucher, O., Servonnat, J., Albright, A. L., Aumont, O., Balkanski, Y., Bastrikov, V., Bekki, S., Bonnet, R., Bony, S., Bopp, L., Braconnot, P., Brockmann, P., Cadule, P., Caubel, A., Cheruy, F., Codron, F., Cozic, A., Cugnet, D., D’Andrea, F., Davini, P., Lavergne, C. de, Denvil, S., Deshayes, J., Devilliers, M., Ducharne, A., Dufresne, J.-L., Dupont, E., Éthé, C., Fairhead, L., Falletti, L., Flavoni, S., Foujols, M.-A., Gardoll, S., Gastineau, G., Ghattas, J., Grandpeix, J.-Y., Guenet, B., Guez, L., E.,

450 Guilyardi, E., Guimberteau, M., Hauglustaine, D., Hourdin, F., Idelkadi, A., Joussaume, S., Kageyama, M., Khodri, M., Krinner, G., Lebas, N., Levavasseur, G., Lévy, C., Li, L., Lott, F., Lurton, T., Luyssaert, S., Madec, G., Madeleine, J.-B., Maignan, F., Marchand, M., Marti, O., Mellul, L., Meurdesoif, Y., Mignot, J., Musat, I., Ottlé, C., Peylin, P., Planton, Y., Polcher, J., Rio, C., Rochetin, N., Rousset, C., Sepulchre, P., Sima, A., Swingedouw, D., Thiéblemont, R., Traore, A. K., Vancoppenolle, M., Vial, J., Vialard, J., Viovy, N., and Vuichard, N.: Presentation and Evaluation of the IPSL-CM6A-LR

455 Climate Model, 12, e2019MS002010, https://doi.org/10.1029/2019MS002010, 2020.

Cakmur, R. V., Miller, R. L., Perlwitz, J., Geogdzhayev, I. V., Ginoux, P., Koch, D., Kohfeld, K. E., Tegen, I., and Zender, C. S.: Constraining the magnitude of the global dust cycle by minimizing the difference between a model and observations, 111, https://doi.org/10.1029/2005JD005791, 2006.

Danabasoglu, G., Lamarque, J.-F., Bacmeister, J., Bailey, D. A., DuVivier, A. K., Edwards, J., Emmons, L. K., Fasullo, J.,

460 Garcia, R., Gettelman, A., Hannay, C., Holland, M. M., Large, W. G., Lauritzen, P. H., Lawrence, D. M., Lenaerts, J. T. M., Lindsay, K., Lipscomb, W. H., Mills, M. J., Neale, R., Oleson, K. W., Otto-Bliesner, B., Phillips, A. S., Sacks, W., Tilmes, S., Kampenhout, L. van, Vertenstein, M., Bertini, A., Dennis, J., Deser, C., Fischer, C., Fox-Kemper, B., Kay, J. E., Kinnison, D., Kushner, P. J., Larson, V. E., Long, M. C., Mickelson, S., Moore, J. K., Nienhouse, E., Polvani, L., Rasch, P. J., and Strand, W. G.: The Community Earth System Model Version 2 (CESM2), 12, e2019MS001916,

465 https://doi.org/10.1029/2019MS001916, 2020.

Evan, A. T., Flamant, C., Fiedler, S., and Doherty, O.: An analysis of aeolian dust in climate models, 41, 5996-6001, https://doi.org/10.1002/2014GL060545, 2014.

Evans, S., Dawson, E., and Ginoux, P.: Linear Relation Between Shifting ITCZ and Dust Hemispheric Asymmetry, Geophys. Res. Lett., 47, https://doi.org/10.1029/2020GL090499, 2020.

470 Eyring, V., Bony, S., Meehl, G. A., Senior, C. A., Stevens, B., Stouffer, R. J., and Taylor, K. E.: Overview of the Coupled Model Intercomparison Project Phase 6 (CMIP6) experimental design and organization, 9, 1937-1958, 2016.

Flato, G., Marotzke, J., Abiodun, B., Braconnot, P., Chou, S. C., Collins, W. J., Cox, P., Driouech, F., Emori, S., and Eyring, V.: Evaluation of Climate Models. In: Climate Change 2013: The Physical Science Basis. Contribution of Working Group I to the Fifth Assessment Report of the Intergovernmental Panel on Climate Change, 5, 741-866, 2013.

475 Gassó, S., Grassian, V. H., and Miller, R. L.: Interactions between Mineral Dust, Climate, and Ocean Ecosystems, Elements, 6, 247-252, https://doi.org/10.2113/gselements.6.4.247, 2010.

Gelaro, R., McCarty, W., Suárez, M. J., Todling, R., Molod, A., Takacs, L., Randles, C. A., Darmenov, A., Bosilovich, M. G., Reichle, R., Wargan, K., Coy, L., Cullather, R., Draper, C., Akella, S., Buchard, V., Conaty, A., Silva, A. M. da, Gu, W., Kim, G.-K., Koster, R., Lucchesi, R., Merkova, D., Nielsen, J. E., Partyka, G., Pawson, S., Putman, W., Rienecker, M., Schubert, S.

480 D., Sienkiewicz, M., and Zhao, B.: The Modern-Era Retrospective Analysis for Research and Applications, Version 2 (MERRA-2), 30, 5419-5454, https://doi.org/10.1175/JCLI-D-16-0758.1, 2017.

Ginoux, P., Chin, M., Tegen, I., Prospero, J. M., Holben, B., Dubovik, O., and Lin, S.-J.: Sources and distributions of dust aerosols simulated with the GOCART model, 106, 20255-20273, https://doi.org/10.1029/2000JD000053, 2001.

Ginoux, P., Prospero, J. M., Gill, T. E., Hsu, N. C., and Zhao, M.: Global-scale attribution of anthropogenic and natural dust

485 sources and their emission rates based on MODIS Deep Blue aerosol products, 50, https://doi.org/10.1029/2012RG000388, 2012.

Gkikas, A., Proestakis, E., Amiridis, V., Kazadzis, S., Di Tomaso, E., Tsekeri, A., Marinou, E., Hatzianastassiou, N., and Pérez García-Pando, C.: ModIs Dust AeroSol (MIDAS): a global fine-resolution dust optical depth data set, 14, 309-334, https://doi.org/10.5194/amt-14-309-2021, 2021.

490 Gliß, J., Mortier, A., Schulz, M., Andrews, E., Balkanski, Y., Bauer, S. E., Benedictow, A. M. K., Bian, H., Checa-Garcia, R., Chin, M., Ginoux, P., Griesfeller, J. J., Heckel, A., Kipling, Z., Kirkevåg, A., Kokkola, H., Laj, P., Le Sager, P., Lund, M. T., Lund Myhre, C., Matsui, H., Myhre, G., Neubauer, D., van Noije, T., North, P., Olivié, D. J. L., Rémy, S., Sogacheva, L., 
Takemura, T., Tsigaridis, K., and Tsyro, S. G.: AeroCom phase III multi-model evaluation of the aerosol life cycle and optical properties using ground- and space-based remote sensing as well as surface in situ observations, Atmos. Chem. Phys., 21, 87-

Hajima, T., Watanabe, M., Yamamoto, A., Tatebe, H., Noguchi, M. A., Abe, M., Ohgaito, R., Ito, A., Yamazaki, D., Okajima, H., Ito, A., Takata, K., Ogochi, K., Watanabe, S., and Kawamiya, M.: Development of the MIROC-ES2L Earth system model and the evaluation of biogeochemical processes and feedbacks, 13, 2197-2244, https://doi.org/10.5194/gmd-13-2197-2020, 2020.

500 Holben, B. N., Eck, T. F., Slutsker, I., Tanré, D., Buis, J. P., Setzer, A., Vermote, E., Reagan, J. A., Kaufman, Y. J., Nakajima, T., Lavenu, F., Jankowiak, I., and Smirnov, A.: AERONET-A Federated Instrument Network and Data Archive for Aerosol Characterization, Remote Sensing of Environment, 66, 1-16, https://doi.org/10.1016/S0034-4257(98)00031-5, 1998.

Huang, Y., Adebiyi, A. A., Formenti, P., and Kok, J. F.: Linking the Different Diameter Types of Aspherical Desert Dust Indicates That Models Underestimate Coarse Dust Emission, 48, e2020GL092054, https://doi.org/10.1029/2020GL092054, 2021.

Huneeus, N., Schulz, M., Balkanski, Y., Griesfeller, J., Prospero, J., Kinne, S., Bauer, S., Boucher, O., Chin, M., Dentener, F., Diehl, T., Easter, R., Fillmore, D., Ghan, S., Ginoux, P., Grini, A., Horowitz, L., Koch, D., Krol, M. C., Landing, W., Liu, X., Mahowald, N., Miller, R., Morcrette, J.-J., Myhre, G., Penner, J., Perlwitz, J., Stier, P., Takemura, T., and Zender, C. S.: Global dust model intercomparison in AeroCom phase I, 11, 7781-7816, https://doi.org/10.5194/acp-11-7781-2011, 2011.

510 Inness, A., Ades, M., Agustí-Panareda, A., Barré, J., Benedictow, A., Blechschmidt, A.-M., Dominguez, J. J., Engelen, R., Eskes, H., and Flemming, J.: The CAMS reanalysis of atmospheric composition, 19, 3515-3556, 2019.

Jin, Q., Wei, J., Lau, W. K. M., Pu, B., and Wang, C.: Interactions of Asian mineral dust with Indian summer monsoon: Recent advances and challenges, Earth-Science Reviews, 215, 103562, https://doi.org/10.1016/j.earscirev.2021.103562, 2021.

Kim, D., Chin, M., Yu, H., Diehl, T., Tan, Q., Kahn, R. A., Tsigaridis, K., Bauer, S. E., Takemura, T., Pozzoli, L., Bellouin,

515 N., Schulz, M., Peyridieu, S., Chédin, A., and Koffi, B.: Sources, sinks, and transatlantic transport of North African dust aerosol: A multimodel analysis and comparison with remote sensing data, 119, 6259-6277, https://doi.org/10.1002/2013JD021099, 2014.

Kim, D., Chin, M., Yu, H., Pan, X., Bian, H., Tan, Q., Kahn, R. A., Tsigaridis, K., Bauer, S. E., Takemura, T., Pozzoli, L., Bellouin, N., and Schulz, M.: Asian and Trans-Pacific Dust: A Multimodel and Multiremote Sensing Observation Analysis,

520 124, 13534-13559, https://doi.org/10.1029/2019JD030822, 2019.

Knippertz, P. and Stuut, J.-B. W. (Eds.): Mineral Dust: A Key Player in the Earth System, Springer Netherlands, https://doi.org/10.1007/978-94-017-8978-3, 2014.

Kok, J. F.: A scaling theory for the size distribution of emitted dust aerosols suggests climate models underestimate the size of the global dust cycle, PNAS, 108, 1016-1021, 2011.

525 Kok, J. F., Ridley, D. A., Zhou, Q., Miller, R. L., Zhao, C., Heald, C. L., Ward, D. S., Albani, S., and Haustein, K.: Smaller desert dust cooling effect estimated from analysis of dust size and abundance, Nature Geosci, 10, 274-278, https://doi.org/10.1038/ngeo2912, 2017.

Kok, J. F., Ward, D. S., Mahowald, N. M., and Evan, A. T.: Global and regional importance of the direct dust-climate feedback, 9, 241, https://doi.org/10.1038/s41467-017-02620-y, 2018.

530 Kok, J. F., Adebiyi, A. A., Albani, S., Balkanski, Y., Checa-Garcia, R., Chin, M., Colarco, P. R., Hamilton, D. S., Huang, Y., Ito, A., Klose, M., Leung, D. M., Li, L., Mahowald, N. M., Miller, R. L., Obiso, V., Pérez García-Pando, C., Rocha-Lima, A., Wan, J. S., and Whicker, C. A.: Improved representation of the global dust cycle using observational constraints on dust properties and abundance, 21, 8127-8167, https://doi.org/10.5194/acp-21-8127-2021, 2021.

Kramer, S. J., Alvarez, C., Barkley, A. E., Colarco, P. R., Custals, L., Delgadillo, R., Gaston, C. J., Govindaraju, R., and

535 Zuidema, P.: Apparent dust size discrepancy in aerosol reanalysis in north African dust after long-range transport, 20, 1004710062, https://doi.org/10.5194/acp-20-10047-2020, 2020.

Li, L., Mahowald, N. M., Miller, R. L., Pérez García-Pando, C., Klose, M., Hamilton, D. S., Gonçalves Ageitos, M., Ginoux, P., Balkanski, Y., Green, R. O., Kalashnikova, O., Kok, J. F., Obiso, V., Paynter, D., and Thompson, D. R.: Quantifying the range of the dust direct radiative effect due to source mineralogy uncertainty, 21, 3973-4005, https://doi.org/10.5194/acp-21-

540 3973-2021, 2021.

Liu, X., Ma, P.-L., Wang, H., Tilmes, S., Singh, B., Easter, R., Ghan, S., and Rasch, P.: Description and evaluation of a new 4-mode version of Modal Aerosol Module (MAM4) within version 5.3 of the Community Atmosphere Model, 8, 2015.

Maharana, P., Dimri, A. P., and Choudhary, A.: Redistribution of Indian summer monsoon by dust aerosol forcing, Meteorol Appl, 26, 584-596, https://doi.org/10.1002/met.1786, 2019.

545 Mahowald, N., Albani, S., Kok, J. F., Engelstaeder, S., Scanza, R., Ward, D. S., and Flanner, M. G.: The size distribution of desert dust aerosols and its impact on the Earth system, Aeolian Research, 15, 53-71, https://doi.org/10.1016/j.aeolia.2013.09.002, 2014. 
Mahowald, N. M., Kloster, S., Engelstaedter, S., Moore, J. K., Mukhopadhyay, S., McConnell, J. R., Albani, S., Doney, S. C., Bhattacharya, A., Curran, M. A. J., Flanner, M. G., Hoffman, F. M., Lawrence, D. M., Lindsay, K., Mayewski, P. A., Neff, J.,

550 Rothenberg, D., Thomas, E., Thornton, P. E., and Zender, C. S.: Observed 20th century desert dust variability: impact on climate and biogeochemistry, Atmos. Chem. Phys., 10, 10875-10893, https://doi.org/10.5194/acp-10-10875-2010, 2010.

Marticorena, B. and Bergametti, G.: Modeling the atmospheric dust cycle: 1. Design of a soil-derived dust emission scheme, 100, 16415-16430, https://doi.org/10.1029/95JD00690, 1995.

Miller, R. L., Cakmur, R. V., Perlwitz, J., Geogdzhayev, I. V., Ginoux, P., Koch, D., Kohfeld, K. E., Prigent, C., Ruedy, R.,

555 Schmidt, G. A., and Tegen, I.: Mineral dust aerosols in the NASA Goddard Institute for Space Sciences ModelE atmospheric general circulation model, 111, https://doi.org/10.1029/2005JD005796, 2006.

Molod, A., Takacs, L., Suarez, M., and Bacmeister, J.: Development of the GEOS-5 atmospheric general circulation model: evolution from MERRA to MERRA2, 8, 1339-1356, https://doi.org/10.5194/gmd-8-1339-2015, 2015.

Mulcahy, J. P., Johnson, C., Jones, C. G., Povey, A. C., Scott, C. E., Sellar, A., Turnock, S. T., Woodhouse, M. T., Abraham,

560 N. L., Andrews, M. B., Bellouin, N., Browse, J., Carslaw, K. S., Dalvi, M., Folberth, G. A., Glover, M., Grosvenor, D. P., Hardacre, C., Hill, R., Johnson, B., Jones, A., Kipling, Z., Mann, G., Mollard, J., O’Connor, F. M., Palmiéri, J., Reddington, C., Rumbold, S. T., Richardson, M., Schutgens, N. A. J., Stier, P., Stringer, M., Tang, Y., Walton, J., Woodward, S., and Yool, A.: Description and evaluation of aerosol in UKESM1 and HadGEM3-GC3.1 CMIP6 historical simulations, Geosci. Model Dev., 13, 6383-6423, https://doi.org/10.5194/gmd-13-6383-2020, 2020.

565 N'Datchoh, E. T., Diallo, I., Konaré, A., Silué, S., Ogunjobi, K. O., Diedhiou, A., and Doumbia, M.: Dust induced changes on the West African summer monsoon features, 38, 452-466, https://doi.org/10.1002/joc.5187, 2018.

$\mathrm{Pu}, \mathrm{B}$. and Ginoux, P.: How reliable are CMIP5 models in simulating dust optical depth?, Atmos. Chem. Phys., 18, 1249112510, https://doi.org/10.5194/acp-18-12491-2018, 2018.

Rind, D., Orbe, C., Jonas, J., Nazarenko, L., Zhou, T., Kelley, M., Lacis, A., Shindell, D., Faluvegi, G., Romanou, A., Russell,

570 G., Tausnev, N., Bauer, M., and Schmidt, G.: GISS Model E2.2: A Climate Model Optimized for the Middle AtmosphereModel Structure, Climatology, Variability, and Climate Sensitivity, 125, e2019JD032204, https://doi.org/10.1029/2019JD032204, 2020.

Ryder, C. L., Highwood, E. J., Walser, A., Seibert, P., Philipp, A., and Weinzierl, B.: Coarse and giant particles are ubiquitous in Saharan dust export regions and are radiatively significant over the Sahara, 19, 15353-15376, https://doi.org/10.5194/acp-

575 19-15353-2019, 2019

Sanap, S. D., Ayantika, D. C., Pandithurai, G., and Niranjan, K.: Assessment of the aerosol distribution over Indian subcontinent in CMIP5 models, Atmospheric Environment, 87, 123-137, https://doi.org/10.1016/j.atmosenv.2014.01.017, 2014.

Seabold, S. and Perktold, J.: Statsmodels: Econometric and Statistical Modeling with Python, 92-96, https://doi.org/10.25080/Majora-92bf1922-011, 2010.

Séférian, R., Nabat, P., Michou, M., Saint-Martin, D., Voldoire, A., Colin, J., Decharme, B., Delire, C., Berthet, S., Chevallier, M., Sénési, S., Franchisteguy, L., Vial, J., Mallet, M., Joetzjer, E., Geoffroy, O., Guérémy, J.-F., Moine, M.-P., Msadek, R., Ribes, A., Rocher, M., Roehrig, R., Salas-y-Mélia, D., Sanchez, E., Terray, L., Valcke, S., Waldman, R., Aumont, O., Bopp, L., Deshayes, J., Éthé, C., and Madec, G.: Evaluation of CNRM Earth System Model, CNRM-ESM2-1: Role of Earth System

585 Processes in Present-Day and Future Climate, 11, 4182-4227, https://doi.org/10.1029/2019MS001791, 2019.

Seland, Ø., Bentsen, M., Olivié, D., Toniazzo, T., Gjermundsen, A., Graff, L. S., Debernard, J. B., Gupta, A. K., He, Y.-C., Kirkevåg, A., Schwinger, J., Tjiputra, J., Aas, K. S., Bethke, I., Fan, Y., Griesfeller, J., Grini, A., Guo, C., Ilicak, M., Karset, I. H. H., Landgren, O., Liakka, J., Moseid, K. O., Nummelin, A., Spensberger, C., Tang, H., Zhang, Z., Heinze, C., Iversen, T., and Schulz, M.: Overview of the Norwegian Earth System Model (NorESM2) and key climate response of CMIP6 DECK, 590 historical, and scenario simulations, 13, 6165-6200, https://doi.org/10.5194/gmd-13-6165-2020, 2020.

Senior, C. A., Jones, C. G., Wood, R. A., Sellar, A., Belcher, S., Klein-Tank, A., Sutton, R., Walton, J., Lawrence, B., Andrews, T., and Mulcahy, J. P.: U.K. Community Earth System Modeling for CMIP6, 12, e2019MS002004, https://doi.org/10.1029/2019MS002004, 2020.

Shao, Y., Wyrwoll, K.-H., Chappell, A., Huang, J., Lin, Z., McTainsh, G. H., Mikami, M., Tanaka, T. Y., Wang, X., and Yoon,

595 S.: Dust cycle: An emerging core theme in Earth system science, Aeolian Research, 2, 181-204, https://doi.org/10.1016/j.aeolia.2011.02.001, 2011.

Skonieczny, C., McGee, D., Winckler, G., Bory, A., Bradtmiller, L. I., Kinsley, C. W., Polissar, P. J., De Pol-Holz, R., Rossignol, L., and Malaizé, B.: Monsoon-driven Saharan dust variability over the past 240,000 years, Sci. Adv., 5, eaav1887, https://doi.org/10.1126/sciadv.aav1887, 2019.

600 Sogacheva, L., Popp, T., Sayer, A. M., Dubovik, O., Garay, M. J., Heckel, A., Hsu, N. C., Jethva, H., Kahn, R. A., Kolmonen, P., Kosmale, M., de Leeuw, G., Levy, R. C., Litvinov, P., Lyapustin, A., North, P., Torres, O., and Arola, A.: Merging regional and global aerosol optical depth records from major available satellite products, 20, 2031-2056, https://doi.org/10.5194/acp20-2031-2020, 2020. 
Sperber, K. R., Annamalai, H., Kang, I.-S., Kitoh, A., Moise, A., Turner, A., Wang, B., and Zhou, T.: The Asian summer monsoon: an intercomparison of CMIP5 vs. CMIP3 simulations of the late 20th century, Clim Dyn, 41, 2711-2744, https://doi.org/10.1007/s00382-012-1607-6, 2013.

Swart, N. C., Cole, J. N. S., Kharin, V. V., Lazare, M., Scinocca, J. F., Gillett, N. P., Anstey, J., Arora, V., Christian, J. R., Hanna, S., Jiao, Y., Lee, W. G., Majaess, F., Saenko, O. A., Seiler, C., Seinen, C., Shao, A., Sigmond, M., Solheim, L., von Salzen, K., Yang, D., and Winter, B.: The Canadian Earth System Model version 5 (CanESM5.0.3), 12, 4823-4873,

610 https://doi.org/10.5194/gmd-12-4823-2019, 2019.

Takemura, T., Okamoto, H., Maruyama, Y., Numaguti, A., Higurashi, A., and Nakajima, T.: Global three-dimensional simulation of aerosol optical thickness distribution of various origins, 105, 17853-17873, https://doi.org/10.1029/2000JD900265, 2000.

Tanaka, T. Y. and Chiba, M.: Global Simulation of Dust Aerosol with a Chemical Transport Model, MASINGAR, 83A, 255-

615 278, https://doi.org/10.2151/jmsj.83A.255, 2005.

Volodin, E. and Gritsun, A.: Simulation of observed climate changes in 1850-2014 with climate model INM-CM5, 9, 12351242, https://doi.org/10.5194/esd-9-1235-2018, 2018.

Volodin, E. M. and Kostrykin, S. V.: The aerosol module in the INM RAS climate model, Russ. Meteorol. Hydrol., 41, 519528, https://doi.org/10.3103/S106837391608001X, 2016.

620 Volodin, E. M., Mortikov, E. V., Kostrykin, S. V., Galin, V. Y., Lykossov, V. N., Gritsun, A. S., Diansky, N. A., Gusev, A. V., Iakovlev, N. G., Shestakova, A. A., and Emelina, S. V.: Simulation of the modern climate using the INM-CM48 climate model, 33, 367-374, https://doi.org/10.1515/rnam-2018-0032, 2018.

Voss, K. K. and Evan, A. T.: A New Satellite-Based Global Climatology of Dust Aerosol Optical Depth, 59, 83-102, https://doi.org/10.1175/JAMC-D-19-0194.1, 2020.

625 Wilcox, L. J., Liu, Z., Samset, B. H., Hawkins, E., Lund, M. T., Nordling, K., Undorf, S., Bollasina, M., Ekman, A. M. L., Krishnan, S., Merikanto, J., and Turner, A. G.: Accelerated increases in global and Asian summer monsoon precipitation from future aerosol reductions, 20, 11955-11977, https://doi.org/10.5194/acp-20-11955-2020, 2020.

Williams, K. D., Copsey, D., Blockley, E. W., Bodas-Salcedo, A., Calvert, D., Comer, R., Davis, P., Graham, T., Hewitt, H. T., Hill, R., Hyder, P., Ineson, S., Johns, T. C., Keen, A. B., Lee, R. W., Megann, A., Milton, S. F., Rae, J. G. L., Roberts, M.

630 J., Scaife, A. A., Schiemann, R., Storkey, D., Thorpe, L., Watterson, I. G., Walters, D. N., West, A., Wood, R. A., Woollings, T., and Xavier, P. K.: The Met Office Global Coupled Model 3.0 and 3.1 (GC3.0 and GC3.1) Configurations, 10, 357-380, https://doi.org/10.1002/2017MS001115, 2018.

Woodward, S.: Modeling the atmospheric life cycle and radiative impact of mineral dust in the Hadley Centre climate model, 106, 18155-18166, https://doi.org/10.1029/2000JD900795, 2001.

635 Wu, C., Lin, Z., Liu, X., Li, Y., Lu, Z., and Wu, M.: Can Climate Models Reproduce the Decadal Change of Dust Aerosol in East Asia?, Geophys. Res. Lett., 45, 9953-9962, https://doi.org/10.1029/2018GL079376, 2018.

Wu, C., Lin, Z., and Liu, X.: The global dust cycle and uncertainty in CMIP5 (Coupled Model Intercomparison Project phase 5) models, Atmos. Chem. Phys., 20, 10401-10425, https://doi.org/10.5194/acp-20-10401-2020, 2020a.

Wu, M., Liu, X., Yang, K., Luo, T., Wang, Z., Wu, C., Zhang, K., Yu, H., and Darmenov, A.: Modeling Dust in East Asia by

640 CESM and Sources of Biases, J. Geophys. Res. Atmos., 124, 8043-8064, https://doi.org/10.1029/2019JD030799, 2019.

Wu, M., Liu, X., Yu, H., Wang, H., Shi, Y., Yang, K., Darmenov, A., Wu, C., Wang, Z., Luo, T., Feng, Y., and Ke, Z.: Understanding processes that control dust spatial distributions with global climate models and satellite observations, Atmos. Chem. Phys., 20, 13835-13855, https://doi.org/10.5194/acp-20-13835-2020, 2020 b.

Yu, H., Chin, M., Yuan, T., Bian, H., Remer, L. A., Prospero, J. M., Omar, A., Winker, D., Yang, Y., Zhang, Y., Zhang, Z.,

645 and Zhao, C.: The fertilizing role of African dust in the Amazon rainforest: A first multiyear assessment based on data from Cloud-Aerosol Lidar and Infrared Pathfinder Satellite Observations, 42, 1984-1991, https://doi.org/10.1002/2015GL063040, 2015.

Yukimoto, S., Kawai, H., Koshiro, T., Oshima, N., Yoshida, K., Urakawa, S., Tsujino, H., Deushi, M., Tanaka, T., Hosaka, M., Yabu, S., Yoshimura, H., Shindo, E., Mizuta, R., Obata, A., Adachi, Y., and Ishii, M.: The Meteorological Research

650 Institute Earth System Model Version 2.0, MRI-ESM2.0: Description and Basic Evaluation of the Physical Component, 97, 931-965, https://doi.org/10.2151/jmsj.2019-051, 2019. 
Table 1: summary of models and simulations used in this study.

\begin{tabular}{|c|c|c|c|c|c|c|}
\hline $\mathbf{o}$ & Models & $\begin{array}{l}\text { Ensemble } \\
\text { members }\end{array}$ & $\begin{array}{l}\text { Resolutio } \\
\text { n } \\
\text { (Lat x lon } \\
x \text { Lev) }\end{array}$ & $\begin{array}{l}\text { Dust size diameter } \\
\text { boundaries }(\mu \mathrm{m})\end{array}$ & Dust emission scheme & Model references \\
\hline a & CESM2-CAM & 10 & $\begin{array}{l}0.9^{\circ} \times 1.25 \\
{ }^{\circ} \times 32 \mathrm{~L}\end{array}$ & \multirow{4}{*}{$\begin{array}{l}\text { Three modes: } \\
\text { Aikten: 0.01-0.1; } \\
\text { Accumulation: } 0.1-1.0 ; \\
\text { Coarse: } 1.0-10.0\end{array}$} & \multirow{4}{*}{ Zender et al., (2003) } & \multirow{4}{*}{$\begin{array}{l}\text { Liu et al., (2015) } \\
\text { Danabasoglu et al., } \\
(2020)\end{array}$} \\
\hline $\mathrm{b}$ & $\begin{array}{l}\text { CESM2-CAM- } \\
\text { FV2 }\end{array}$ & 3 & $\begin{array}{l}1.9^{\circ} \times 2.5^{\circ} \\
\times 32 \mathrm{~L}\end{array}$ & & & \\
\hline c & $\begin{array}{l}\text { CESM2- } \\
\text { WACCM }\end{array}$ & 3 & $\begin{array}{l}0.9^{\circ} \mathrm{x} \\
1.25^{\circ} \times 70 \\
\mathrm{~L}\end{array}$ & & & \\
\hline d & $\begin{array}{l}\text { CESM2- } \\
\text { WACCM-FV2 }\end{array}$ & 3 & $\begin{array}{l}1.9^{\circ} \times 2.5 \mathrm{x} \\
70 \mathrm{~L}\end{array}$ & & & \\
\hline e & CNRM-ESM2-1 & 1 & $\begin{array}{l}1.4^{\circ} \times 1.41 \\
{ }^{\circ} \times 90 \mathrm{~L}\end{array}$ & $\begin{array}{l}3 \text { bins: } 0.01-1.0,1.0-2.5 \\
2.5-20\end{array}$ & $\begin{array}{l}\text { Marticorena } \\
\text { Bergametti (1995) } \\
\text { Kok (2011) }\end{array}$ & $\begin{array}{l}\text { Séférian et al., } \\
(2019)\end{array}$ \\
\hline f & CanESM5 & 5 & $\begin{array}{l}2.8^{\circ} \times 2.8^{\circ} \\
\times 49 \mathrm{~L}\end{array}$ & Bulk concentrations & $\begin{array}{ll}\text { Marticorena } & \text { and } \\
\text { Bergametti (1995) } & \end{array}$ & Swart et al., (2019) \\
\hline $\mathrm{g}$ & GISS-E2-1-G & 5 & $\begin{array}{l}2^{\circ} \times 2.5^{\circ} \times 4 \\
0 \mathrm{~L}\end{array}$ & \multirow{2}{*}{$\begin{array}{l}6 \text { bins: }<1,1-2,2-4,4-8,8- \\
16,16-32\end{array}$} & \multirow{2}{*}{$\begin{array}{l}\text { Cakmur et al., (2006) } \\
\text { Miller et al., (2006) }\end{array}$} & Bauer et al., (2020) \\
\hline $\mathrm{h}$ & GISS-E2-2-G & 5 & $\begin{array}{l}2^{\circ} \times 2.5^{\circ} \times 1 \\
02 \mathrm{~L}\end{array}$ & & & Rind et al., (2020) \\
\hline i & $\begin{array}{l}\text { HadGEM3- } \\
\text { GC31-LL }\end{array}$ & 1 & $\begin{array}{l}1.25^{\circ} \times 1.8 \\
75^{\circ} \times 85 \mathrm{~L}\end{array}$ & $\begin{array}{l}6 \text { bins : } 0.064-0.2,0.2-0.63 \\
0.63-2.0,2.0-6.32,6.32-20 \\
20-63\end{array}$ & $\begin{array}{l}\text { Marticorena } \\
\text { Bergametti (1995) } \\
\text { Woodward (2001) }\end{array}$ & $\begin{array}{l}\text { Williams et al., } \\
(2018)\end{array}$ \\
\hline $\mathrm{j}$ & INM-CM4-8 & 1 & $\begin{array}{l}1.5^{\circ} \times 2^{\circ} \times 2 \\
1 \mathrm{~L}\end{array}$ & Bulk concentration & Prescribed & $\begin{array}{l}\text { Volodin et al., } \\
(2018)\end{array}$ \\
\hline $\mathrm{k}$ & INM-CM5-0 & 1 & $\begin{array}{l}1.5^{\circ} \times 2^{\circ} \times 7 \\
3 \mathrm{~L}\end{array}$ & Bulk concentration & $\begin{array}{l}\text { Volodin and kostrykin } \\
\text { (2016) }\end{array}$ & $\begin{array}{l}\text { Volodin and } \\
\text { Gritsun (2018) }\end{array}$ \\
\hline 1 & IPSL-CM6A-LR & 4 & $\begin{array}{l}1.26^{\circ} \times 2.5 \\
{ }^{\circ} \times 79 \mathrm{~L}\end{array}$ & $\begin{array}{l}4 \text { lognormal modes with } \\
\text { mass median diameter } \\
\text { (geometric } \\
\text { deviation):1 (1.8), } 2.5(2), 7 \\
(1.9) \text {, and } 22(2)\end{array}$ & Biagio et al. (2020) & $\begin{array}{l}\text { Boucher et al., } \\
(2020)\end{array}$ \\
\hline
\end{tabular}




\begin{tabular}{|c|c|c|c|c|c|c|}
\hline $\mathrm{m}$ & MIROC-ES2L & 2 & $\begin{array}{l}4.5^{\circ} \times 2.8^{\circ} \\
\times 40 \mathrm{~L}\end{array}$ & $\begin{array}{l}10 \text { bins }: 0.1-0.16,0.16- \\
0.25 \\
0.25-0.40,0.40-0.63,0.63- \\
1.00,1.00-1.58,1.58,2.51 \\
2.51-3.98,3.98-6.31,6.31- \\
10\end{array}$ & Takemura et al.(2000) & $\begin{array}{l}\text { Hajima et al., } \\
(2020)\end{array}$ \\
\hline $\mathrm{n}$ & MRI-ESM2-0 & 1 & $\begin{array}{l}1.125^{\circ} \mathrm{x} 1 \\
125^{\circ} \mathrm{x} \\
80 \mathrm{~L}\end{array}$ & $\begin{array}{l}6 \text { bins: } 0.2-2,2-4,4-6,6-8, \\
8-10,10-12,12-20\end{array}$ & Tanaka and Chiba (2005) & $\begin{array}{l}\text { Yukimoto et al., } \\
(2019)\end{array}$ \\
\hline $\mathrm{o}$ & NorESM2-LM & 1 & $\begin{array}{l}1.875^{\circ} \mathrm{x} \\
2.5^{\circ} \times 32 \mathrm{~L}\end{array}$ & Same as CESM2 & Zender et al., (2003) & $\begin{array}{l}\text { Seland et al., } \\
(2020)\end{array}$ \\
\hline $\mathrm{p}$ & UKESM1-0-LL & 1 & $\begin{array}{l}1.25^{\circ} \times 1.8 \\
75^{\circ} \times 85 \mathrm{~L}\end{array}$ & $\begin{array}{l}6 \text { bins :0.064-0.2, 0.2-0.63, } \\
0.63-2.0,2.0-6.32,6.32-20 \\
20-63\end{array}$ & $\begin{array}{l}\text { Marticorena } \\
\text { Bergametti (1995) } \\
\text { Woodward (2001) }\end{array}$ & $\begin{array}{l}\text { Senior et al., } \\
(2020)\end{array}$ \\
\hline & MERRA2 & & $\begin{array}{l}0.5^{\circ} \times 0.62 \\
5^{\circ} \times 72 \mathrm{~L}\end{array}$ & $\begin{array}{l}5 \text { bins: } 0.2-2,2-3.6,3.6-6 \\
6-12,12-20\end{array}$ & Ginoux et al., (2001) & $\begin{array}{l}\text { Randles at al., } \\
(2017)\end{array}$ \\
\hline & CAMS & & $\begin{array}{l}0.75^{\circ} \times 0.7 \\
5^{\circ} \times 60 \mathrm{~L}\end{array}$ & 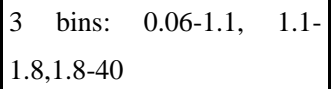 & Ginoux et al., (2001) & $\begin{array}{l}\text { Inness et al., } \\
(2019)\end{array}$ \\
\hline
\end{tabular}


655 Table 2: Global total budgets for dust emission, deposition and burden. Also shown are dust lifetime and global annual mean DOD.

\begin{tabular}{|c|c|c|c|c|c|c|c|c|c|c|}
\hline & \multirow[t]{2}{*}{$\begin{array}{l}\text { Emission } \\
\left(\mathrm{Tg} \mathrm{yr}^{-1}\right)\end{array}$} & \multicolumn{2}{|c|}{$\begin{array}{l}\text { Total } \\
\text { deposition } \\
\left(\mathrm{Tg} \mathrm{yr}^{-1}\right)\end{array}$} & \multicolumn{2}{|c|}{$\begin{array}{l}\text { Dry deposition } \\
\left(\mathrm{Tg} \mathrm{y}^{-1}\right)\end{array}$} & \multicolumn{2}{|c|}{$\begin{array}{l}\text { Wet deposition } \\
\left(\mathrm{Tg} \mathrm{yr}^{-1}\right)\end{array}$} & \multirow[t]{2}{*}{$\begin{array}{l}\text { Bur } \\
\text { den } \\
(\mathrm{Tg})\end{array}$} & \multirow[t]{2}{*}{$\begin{array}{l}\text { Lifetime } \\
\text { (days) }\end{array}$} & \multirow[t]{2}{*}{$\begin{array}{l}\text { DOD } \\
(\#)\end{array}$} \\
\hline & & $\begin{array}{l}\text { Tota } \\
1\end{array}$ & Land $^{\mathrm{a}}$ & Total $^{\text {b }}$ & land $^{\mathrm{c}}$ & Total $^{\mathrm{d}}$ & Land $^{\mathrm{e}}$ & & & \\
\hline CESM2 & 2238 & 2150 & $1606(80)$ & $782(36)$ & $659(82)$ & $1369(64)$ & 947 (69) & 27 & 4.6 & 0.027 \\
\hline CESM2-FV2 & 2577 & 2133 & $1542(72)$ & $768(36)$ & $626(82)$ & $1366(64)$ & 917 (67) & 26 & 4.4 & 0.025 \\
\hline CESM2-WACCM & 2210 & 2100 & $1578(75)$ & $769(37)$ & $649(84)$ & $1341(63)$ & $929(69)$ & 27 & 4.7 & 0.026 \\
\hline $\begin{array}{l}\text { CESM2-WACCM- } \\
\text { FV2 }\end{array}$ & 7050 & 5835 & $4553(78)$ & $2202(38)$ & $1794(81)$ & $3633(62)$ & $2351(65)$ & 74 & 4.6 & 0.073 \\
\hline CNRM-ESM2-1 & 2655 & 2424 & $1926(79)$ & $1672(68)$ & $1415(85)$ & $753(32)$ & $511(68)$ & 14 & 2.1 & 0.011 \\
\hline CanESM5 & 3274 & 2381 & $2082(87)$ & $2056(86)$ & $1830(89)$ & $325(14)$ & $252(77)$ & 10 & 1.5 & 0.027 \\
\hline GISS-E2-1-G & 1639 & 1586 & $1234(78)$ & $1055(67)$ & $924(88)$ & $531(33)$ & $311(59)$ & 23 & 5.3 & 0.023 \\
\hline GISS-E2-2-G & 1560 & 1510 & $1133(75)$ & $1022(68)$ & $880(86)$ & $488(32)$ & $253(52)$ & 28 & 6.8 & 0.028 \\
\hline HadGEM3-GC31-LL & 3255 & 3251 & $2912(89)$ & $2700(83)$ & $2591(96)$ & $551(17)$ & $321(58)$ & 14 & 3.4 & 0.016 \\
\hline INM-CM4-8 & 1374 & 1349 & $923(68)$ & $851(63)$ & 654 (77) & 498 (32) & $269(54)$ & & & 0.033 \\
\hline INM-CM5-0 & 1414 & 1385 & $936(68)$ & $865(62)$ & $660(76)$ & $520(32)$ & $276(53)$ & & & 0.034 \\
\hline IPSL-CM6A-LR & & & & & & & & 21 & & 0.033 \\
\hline MIROC-ES2L & 7571 & 5852 & $5003(85)$ & $4978(85)$ & $4451(89)$ & $902(15)$ & $552(61)$ & 31 & 1.9 & 0.045 \\
\hline MRI-ESM2-0 & 5725 & 5473 & $4512(82)$ & $3575(65)$ & $3253(91)$ & $1898(35)$ & $1259(66)$ & 27 & 1.8 & 0.027 \\
\hline NorESM2-LM & 7092 & & & & & & & 9 & & 0.030 \\
\hline UKESM1-0-LL & 7453 & 7443 & $6923(93)$ & $6518(88)$ & $6288(96)$ & $925(12$ & 635 (69) & 18 & 0.87 & 0.011 \\
\hline AMIP MEM & 3472 & 3201 & $2594(81)$ & $2123(66)$ & $1895(89)$ & $1078(34)$ & 699 (65) & 25 & 2.8 & 0.029 \\
\hline CAMS & 1624 & 6598 & $5119(78)$ & $4548(69)$ & $4069(89)$ & $2050(31)$ & $1050(51)$ & 12 & 0.66 & 0.019 \\
\hline MERRA2 & 1594 & 1607 & $1155(72)$ & $1123(70)$ & $930(83)$ & $485(30)$ & $225(46)$ & 23 & 5.2 & 0.030 \\
\hline
\end{tabular}

a. Numbers in brackets are percentages of total depositions to land relative to global total (dry + wet) depositions

b. Numbers in brackets are percentages of total dry depositions relative to global total (dry + wet) depositions

c. Numbers in brackets are percentages of total dry depositions to land relative to global total dry depositions

660 d. Numbers in brackets are percentages of total wet depositions relative to global total (dry + wet) depositions

e. Numbers in brackets are percentages of total wet depositions relative to global total wet depositions 

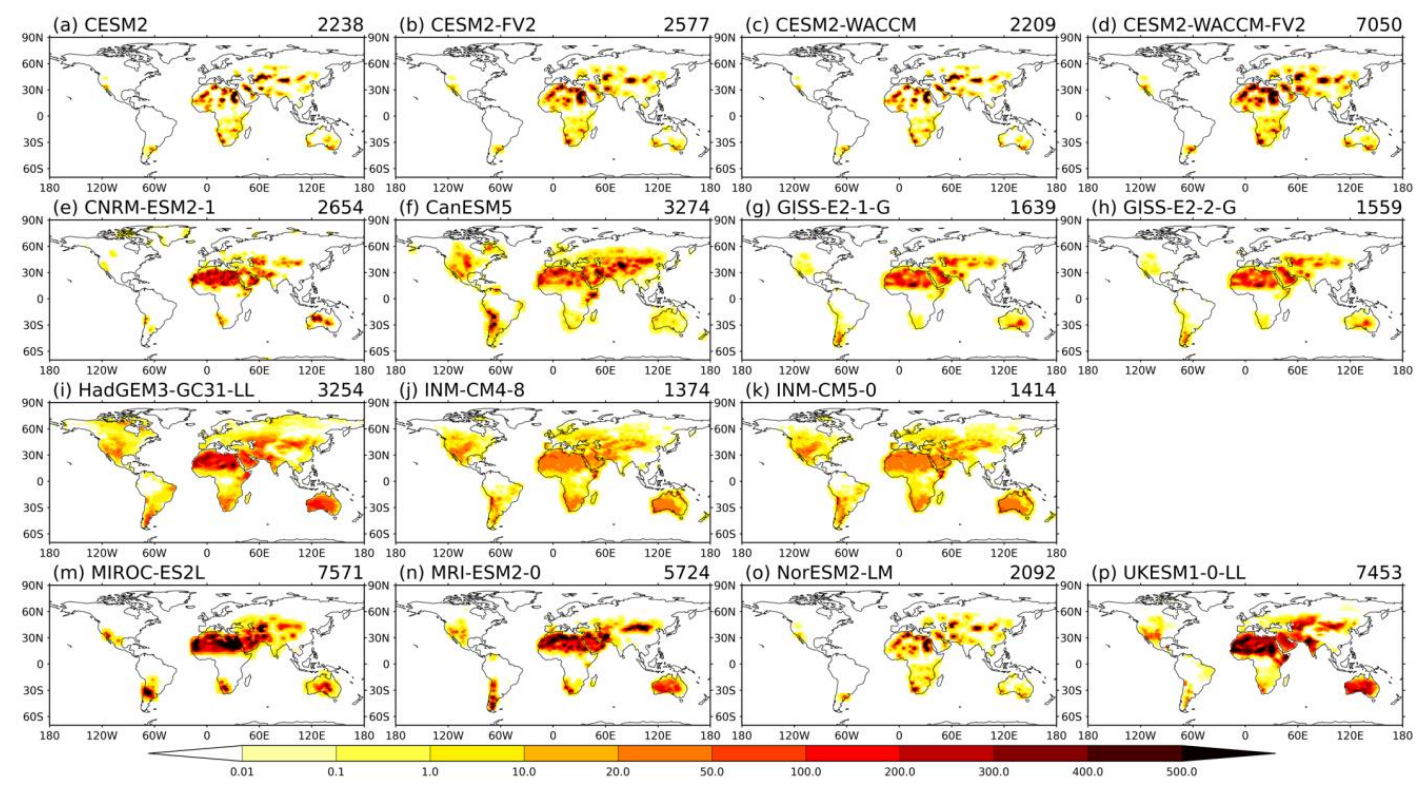

Figure 1: The CMIP6 AMIP models' simulated global annual mean (2005-2014) dust emission $\left(\mathrm{g} \mathrm{m}^{-2} \mathrm{~s}^{-1}\right)$ climatology. The

numbers on the top right of each panel denote the global total dust emission budget $\left(\mathrm{Tg} \mathrm{yr}^{-1}\right)$. 

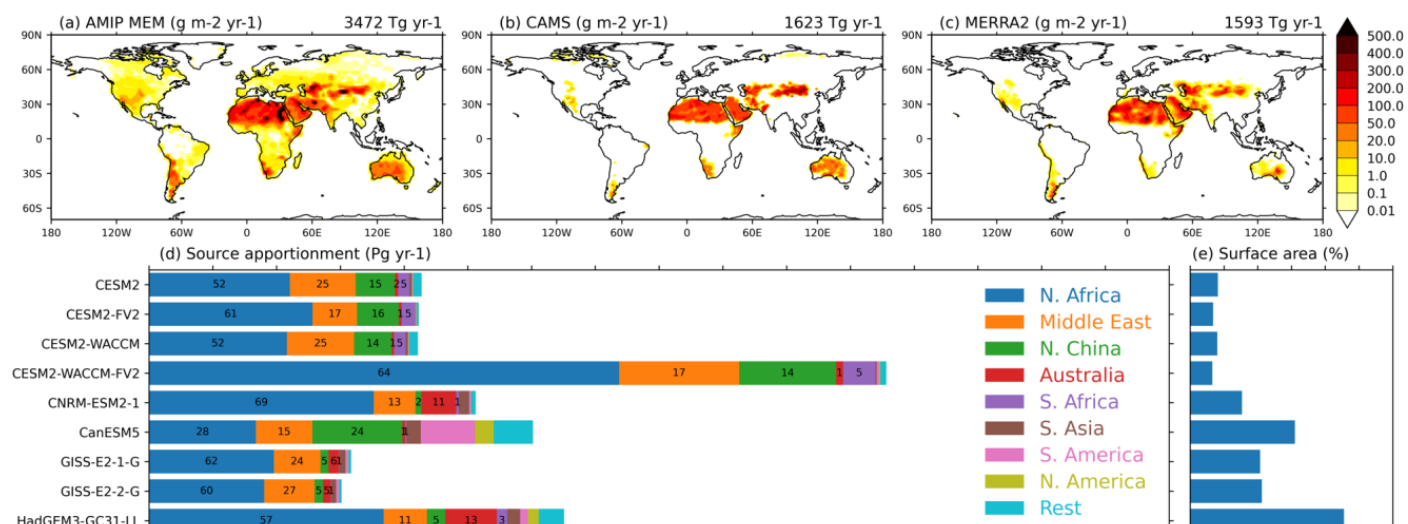

(e) Surface area (\%)

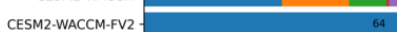

\begin{tabular}{l|l|l|l|}
\hline CNRM-ESM2-1 & 69 & 13 & 211 \\
\hline
\end{tabular}

2]

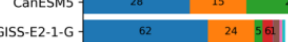

GISS-E2-2-G 60 27 5표

HadGEM3-GC31-LL -

INM-CM4-8 $-32 \quad 136$\begin{tabular}{lll}
\hline 5 & 8
\end{tabular}

INM-CM5-0 $-31 \quad 126 \begin{array}{llll}-37 & 8\end{array}$

MIROC-ES2L-

MRI-ESM2-0 -

NorESM2-LM -

UKESM1-0-LL-

AMIP MEM -

CAMS -
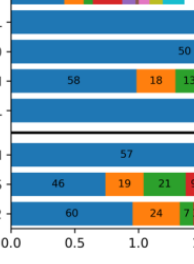

\begin{tabular}{ll|l|l|}
11 & 5 & 13 & 3
\end{tabular}

Figure 2: Intercomparison of 2005-2014 annual mean dust emissions between models and reanalyses. Maps show the annual mean dust emissions ( $\mathrm{g} \mathrm{m}^{-2} \mathrm{yr}^{-1}$ ) from (a) AMIP MEM, (b) CAMS and (c) MERRA2. The numbers on the top right of each

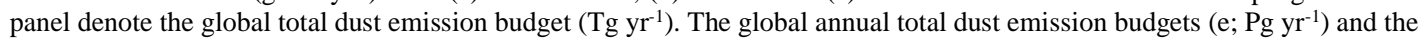
fraction of total dust emission areas relative to the global surface area (f; \%) are shown for each individual model as well as for the AMIP MEM, CAMS and MERRA2. The contributions of major dust source regions are coloured out in (e), where the percentage contributions of the first five largest source regions are given at the centres of each coloured bars. 
https://doi.org/10.5194/acp-2021-578

Preprint. Discussion started: 13 September 2021

(c) Author(s) 2021. CC BY 4.0 License.
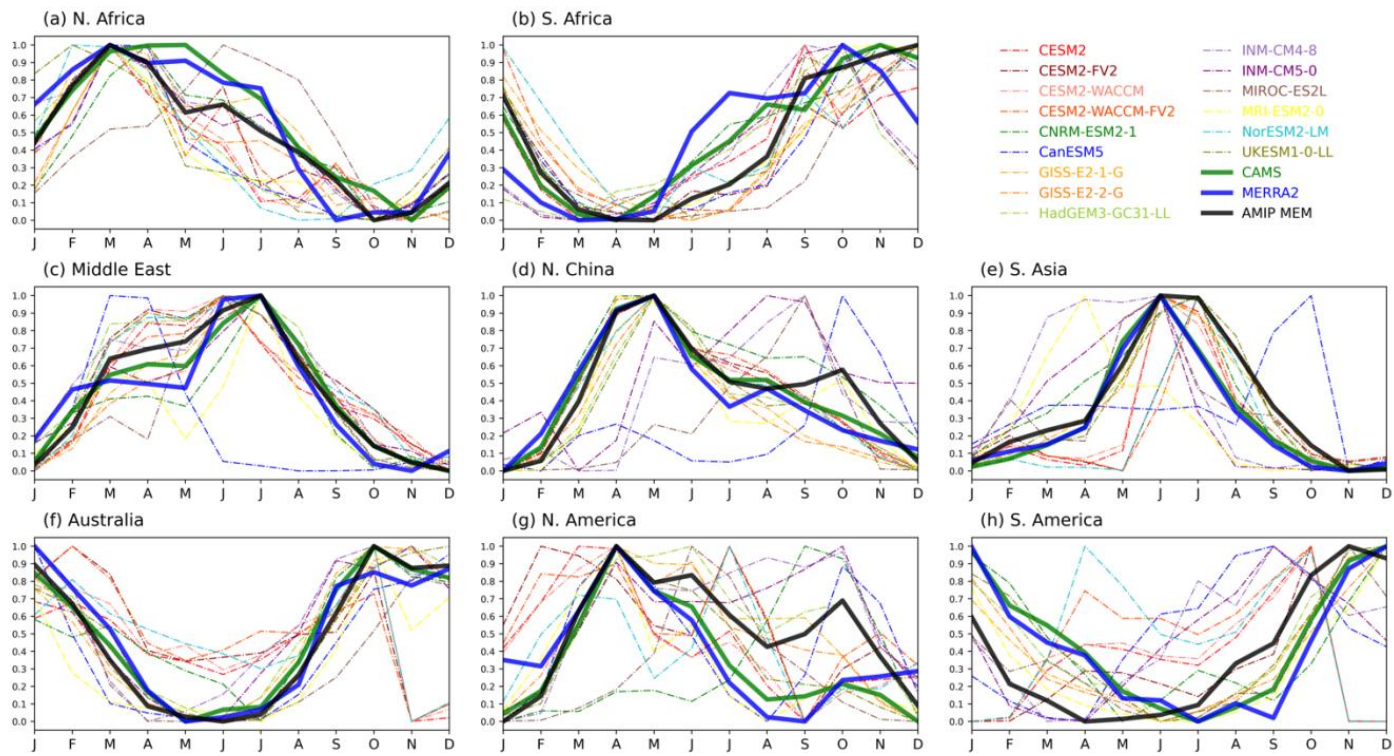

Figure 3: Normalised seasonal cycles of dust emissions over the eight dust source regions. Dashed curves represent individual

models, while the AMIP MEM is shown in solid black. Also shown are results from CAMS (solid green) and MERRA2 (solid blue). The absolute dust emission seasonal cycles are included in Supplementary Figure S2. 
(a) CESM2
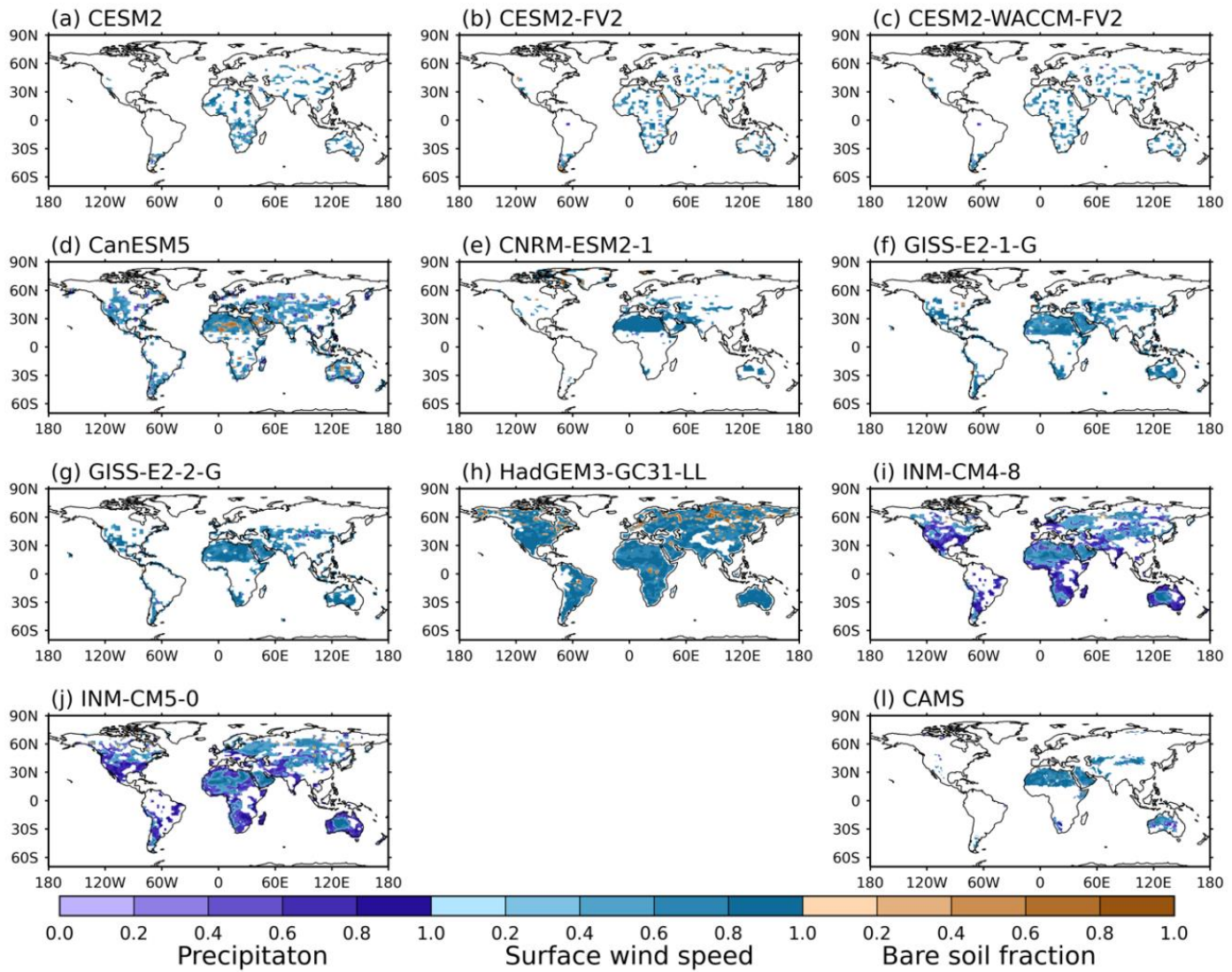

Figure 4: The dominant driver of dust emission and its relative importance (scaled to 0-1) in (a-k) models and (1) CAMS reanalysis. Purple for precipitation, blue for surface wind speed, and brown for bare soil fraction. Data used for regressions are 30 years (1985-2014) for models and 10 years (2005-2014) for CAMS due to data availability. Surface wind speed and precipitation in panel (1) are taken from ERA5. 
(a) N. Africa

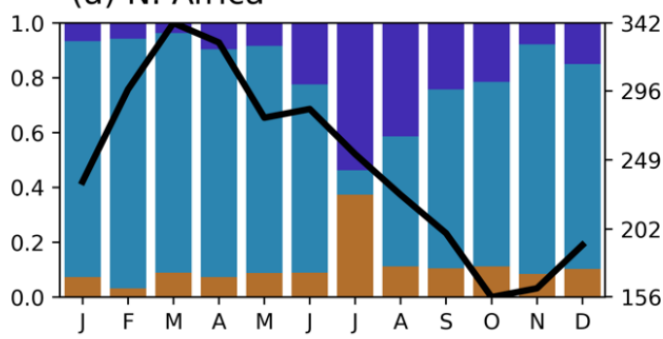

(c) Middle East

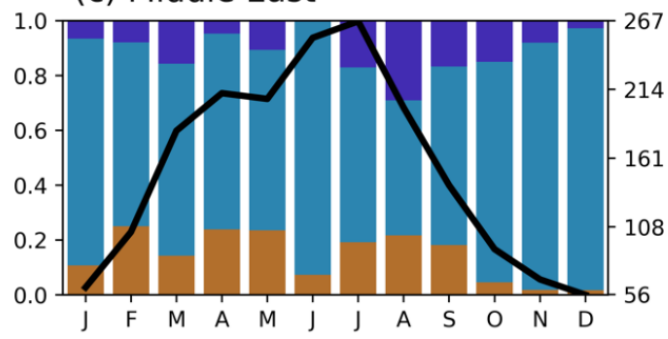

(e) S. Asia

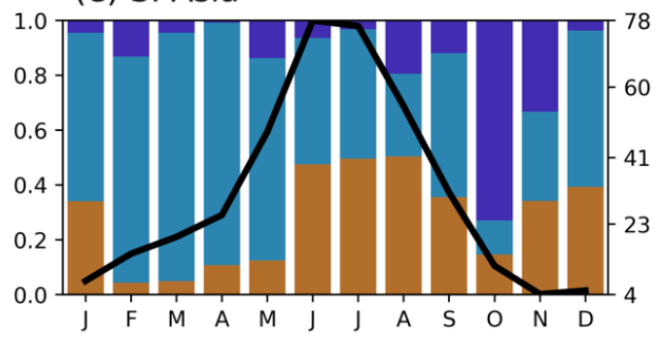

(g) N. America

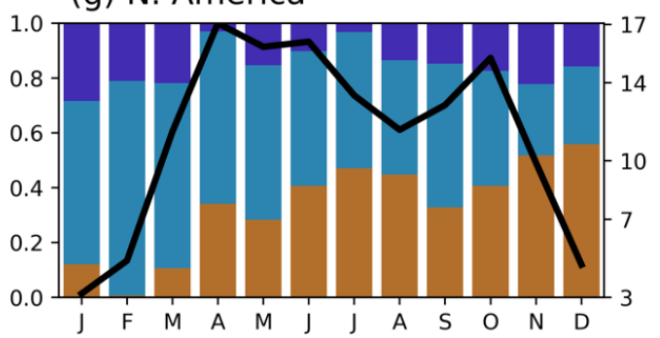

(b) S. Africa

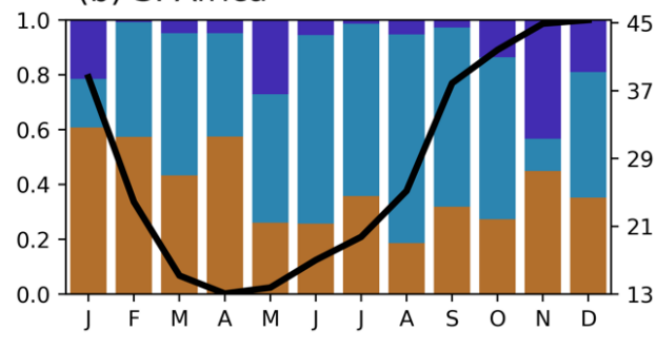

(d) N. China

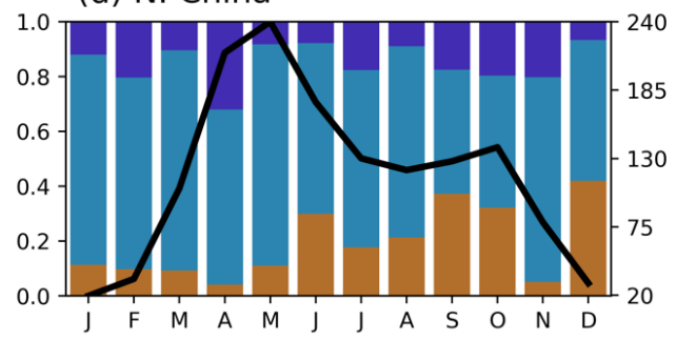

(f) Australia

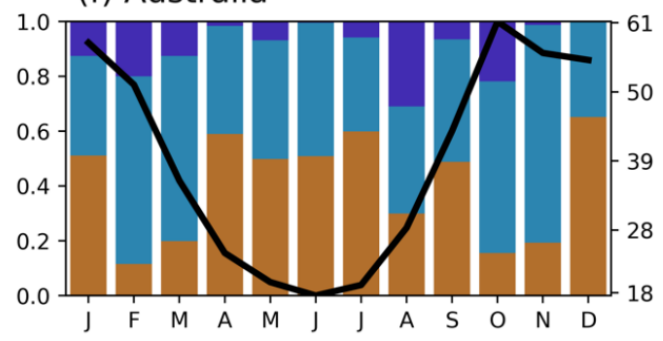

(h) S. America

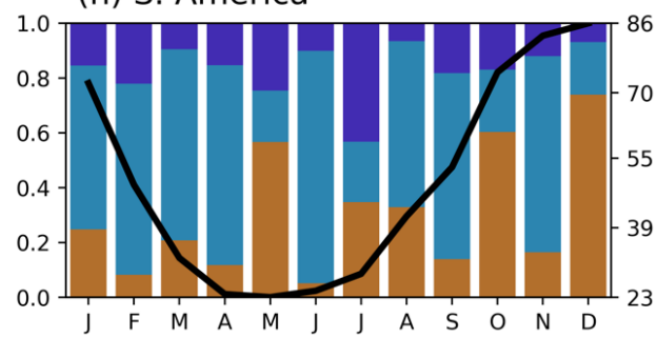

Figure 5: Normalised relative importance (left axis) of the three major dust emission drivers throughout the year over the eight 685 major source regions. Purple for precipitation, blue for surface wind speed, and brown for bare soil fraction. The black curves are AMIP MEM (models in Figure 4) seasonal cycles of dust emissions (right axis; $\mathrm{mg} \mathrm{m}^{-2}$ day $^{-1}$ ). 
(a) AMIP MEM (mg m-2)

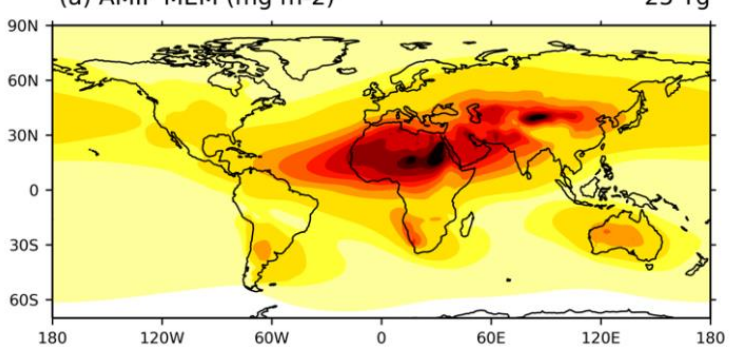

(b) CAMS (mg m-2)

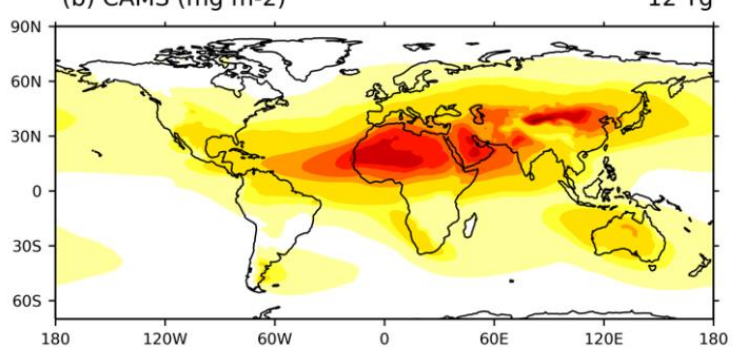

(c) MERRA2 (mg m-2)

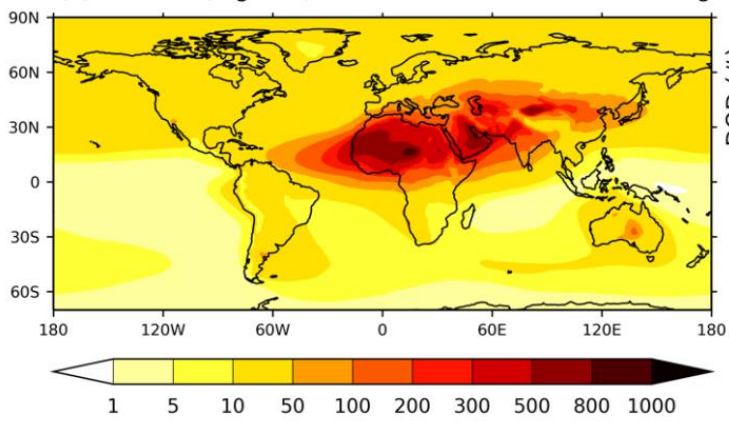

(d) Global dust burden (Tg)

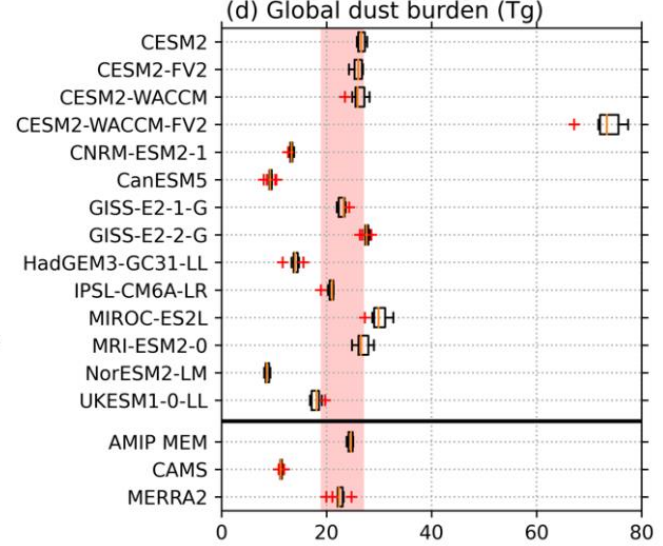

(e) Africa-Alantic [0-35N, 60W-0W]

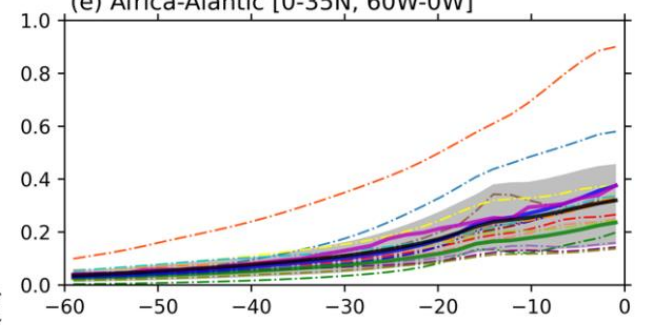

응

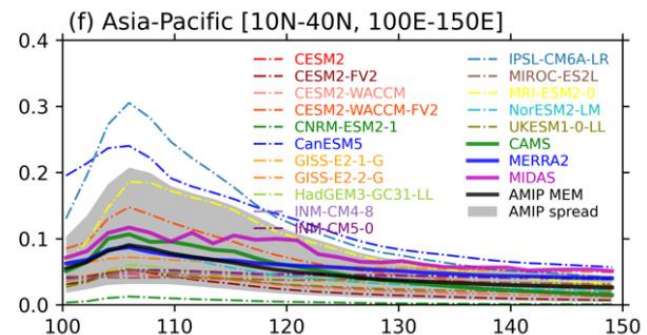

Figure 6: Intercomparison of 2005-2014 annual mean dust mass loading $\left(\mathrm{mg} \mathrm{m}^{-2}\right)$ between (a) AMIP MEM, (b) CAMS and (c) MERRA2. The numbers on the top right of each panel denote the global total dust burden (Tg). Maps for individual models can be found in Supplementary Figure 3. (d) Global total dust burden from each individual model as well as those of (a-c): boxes denote the $10^{\text {th }}-90^{\text {th }}$ percentiles of the annual variability; red pluses denote outliers that are outside 1.5 times of annual standard deviation. The vertical pink shading represents the $10^{\text {th }}-90^{\text {th }}$ percentiles of the multimodal spread. Also shown are the meridionally-averaged DOD over (e) the Africa-Atlantic region $(0-35 \mathrm{~N}, 60 \mathrm{~W}-0 \mathrm{~W})$ in June-July-August and (f) the AsiaPacific region (10-40N, 100E-150E) in April-May-June. 
(a) AMIP MEM total dust deposition

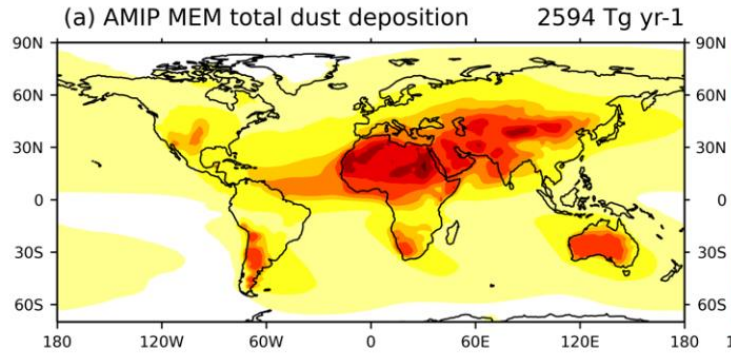

(c) CAMS total dust deposition

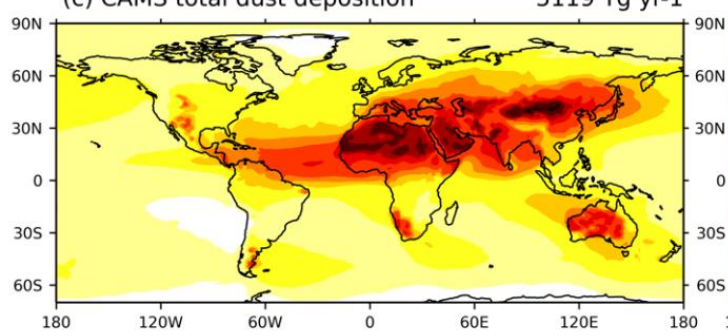

(e) MERRA2 total dust deposition

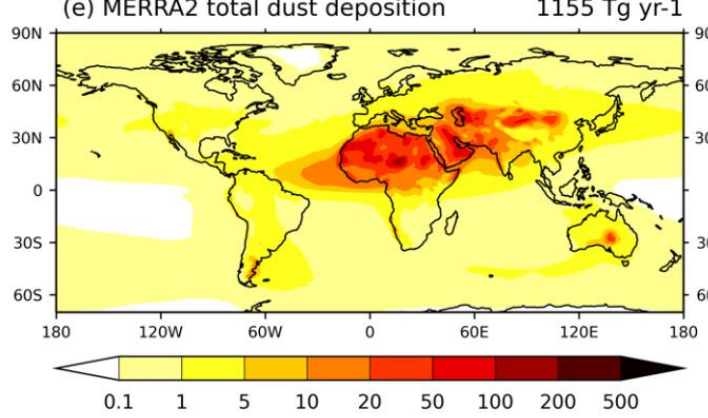

(b) AMIP MEM wet deposition fraction (\%)

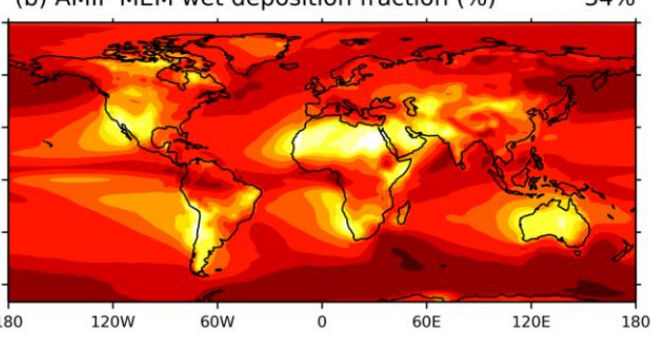

(d) CAMS wet deposition fraction (\%)

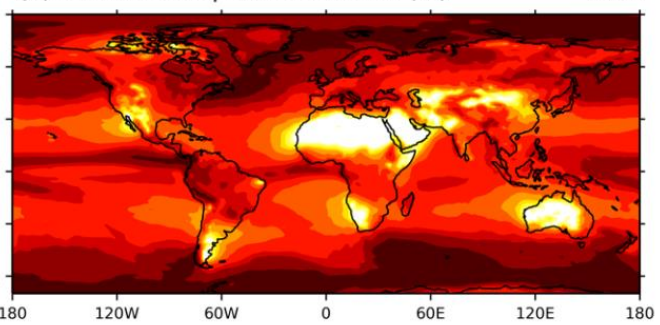

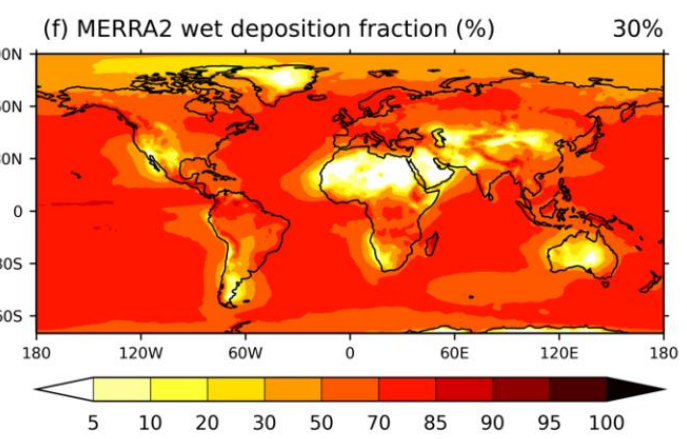

695 Figure 7: Intercomparison of 2005-2014 mean of annual total (dry + wet) dust deposition (left; $\left.\mathrm{g} \mathrm{m}^{-2} \mathrm{yr}^{-1}\right)$ and the ratio of wetto-total depositions (right; \%). Top row for AMIP MEM, middle for CAMS and bottom for MERRA2. The numbers on the top right of each panel denote the global total dust deposition flux $\left(\mathrm{Tg}_{\mathrm{yr}} \mathrm{r}^{-1}\right)$ and the fraction of global wet-to-total dust depositions (\%). 

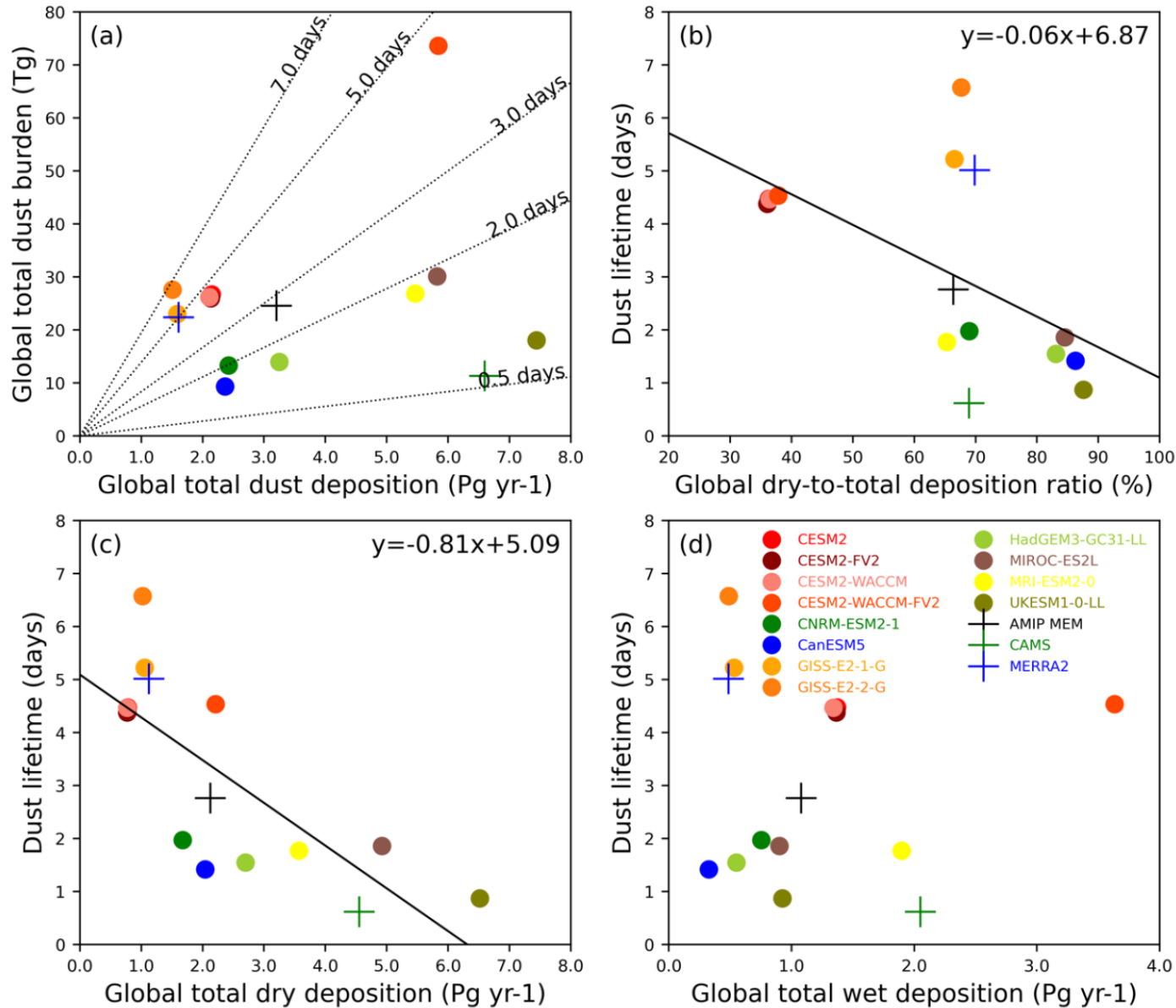

700 Figure 8: Scatterplots of (a) global annual mean total dust burdens (Tg) vs. annual total dust deposition ( $\left.\mathrm{Pg} \mathrm{yr}^{-1}\right)$, and global dust lifetime (days) vs. (b) the ratio of global dry-to-total deposition (\%), (c) total dry depositions $\left(\mathrm{Pg} \mathrm{yr}^{-1}\right)$, and (d) total wet depositions $\left(\mathrm{Pg} \mathrm{yr}^{-1}\right)$. Model colour codes are the same as in other figures, along with AMIP MEM (black plus), CAMS (green plus) and MERRA2 (blue plus). The dotted slope lines in (a) denote dust lifetime intervals (days). The solid slope lines in (b) and (c) are the linear fitting between $\mathrm{X}$ and $\mathrm{Y}$ axis using all data points. All results shown are 2005-2014 annual mean. 
(a) FMI

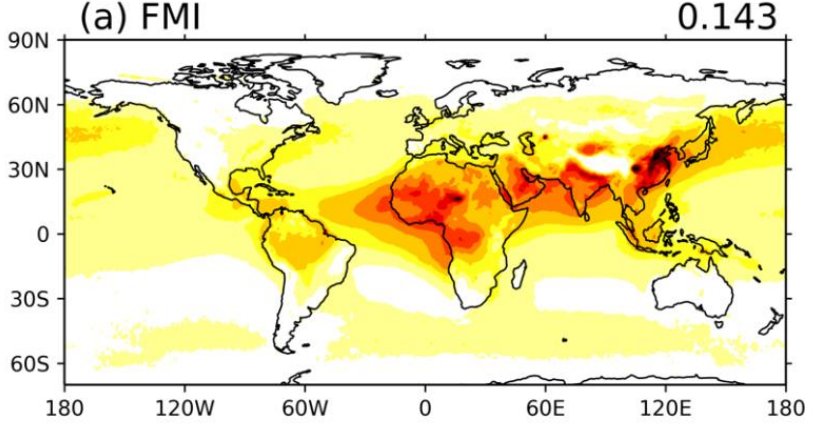

(b) CAMS

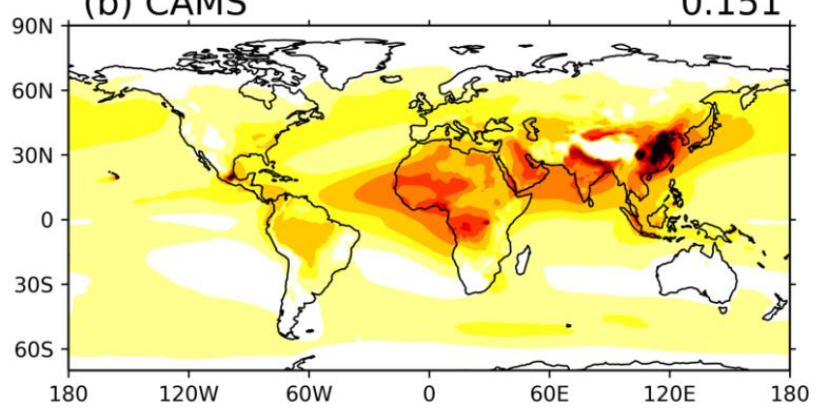

(c) MERRA2

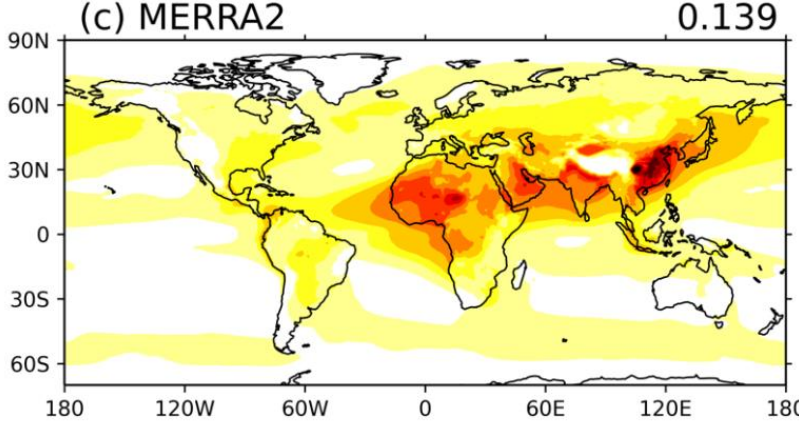

(d) AMIP MEM
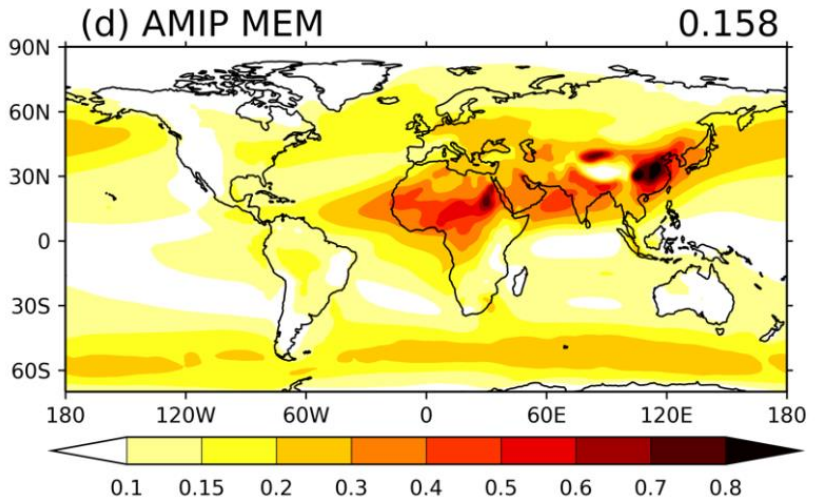

(e) FMI vs. AMIP MEM

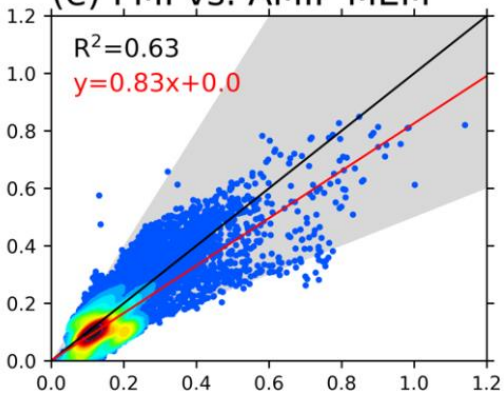

(f) CAMS vs. AMIP MEM
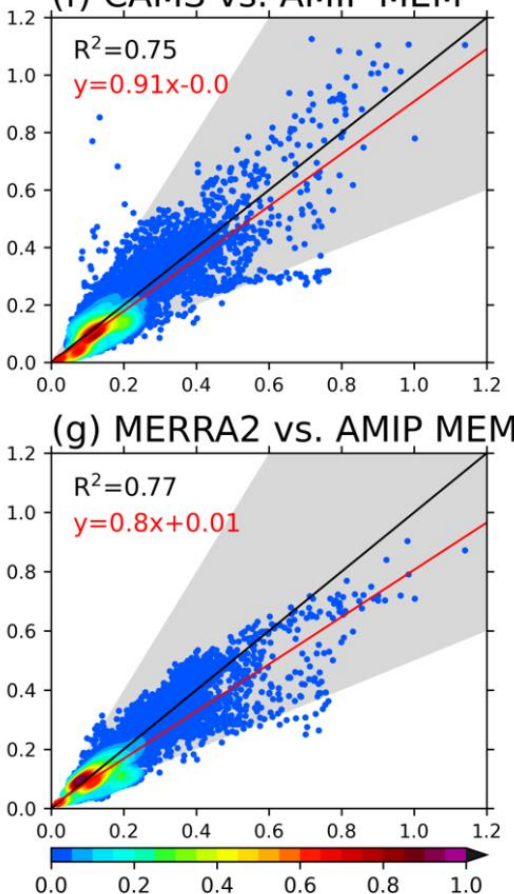

(h) Model performances

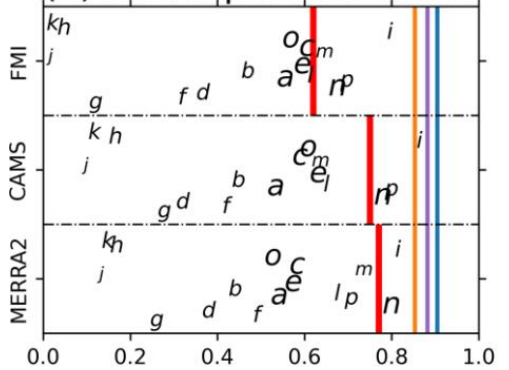

Figure 9: Intercomparison of 2005-2014 annual mean AOD from (a) FMI merged satellite retrievals, (b) CAMS, (c) MERRA2 and (d) AMIP MEM. (e-g) show the density $\left(10^{-4}\right)$ scatter plots of observation/reanalyses (a-c; $y$-axes) vs. AMIP MEM (d; $x$ axes): the black lines are the 1:1 correspondence while the red lines are the linear fitting $\left(\mathrm{R}^{2}\right.$ and the regression equation given at top left corners). (h) is a summary of the performance of each individual model measured by the spatial $\mathrm{R}^{2}$ (X-axis) between

710 each individual model and observation/reanalyses. The Y-axes do not have any physical meaning, and is used to make the plot readable. Models are shown by letters (cf. Table 1). The red vertical bars denote where the AMIP MEM stands. The blue vertical bar shows the spatial $\mathrm{R}^{2}$ between CAMS and FMI. Similarly, orange bars for MERRA2 vs. FMI, and purple for CAMS vs. MERRA2. 

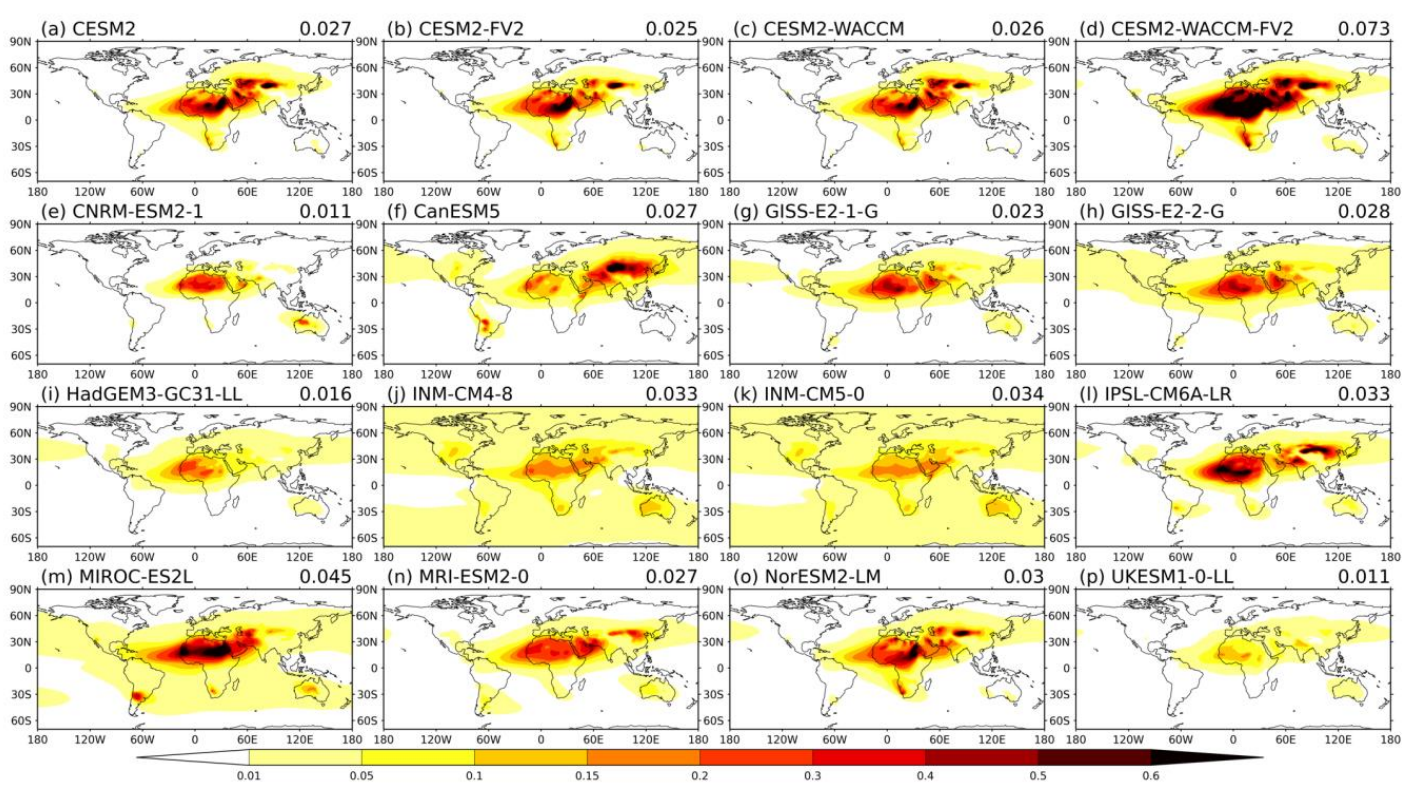

715 Figure 10: The CMIP6 AMIP models' simulated global annual mean (2005-2014) DOD climatology. The numbers on the top right of each panel denote the global means. 
(a) MIDAS

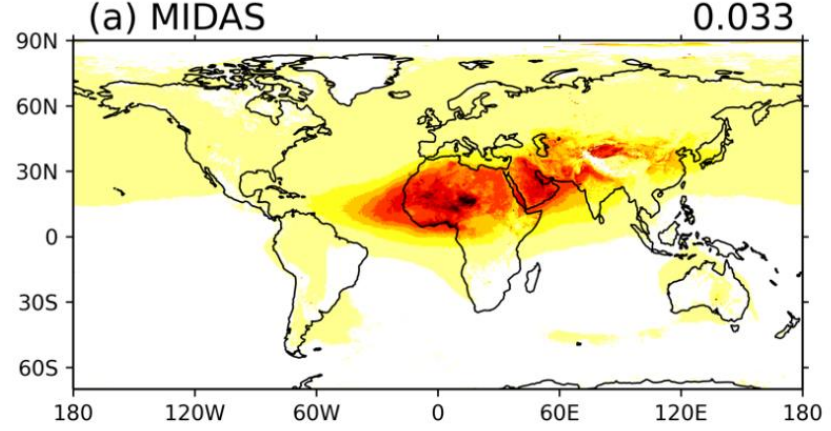

(b) CAMS

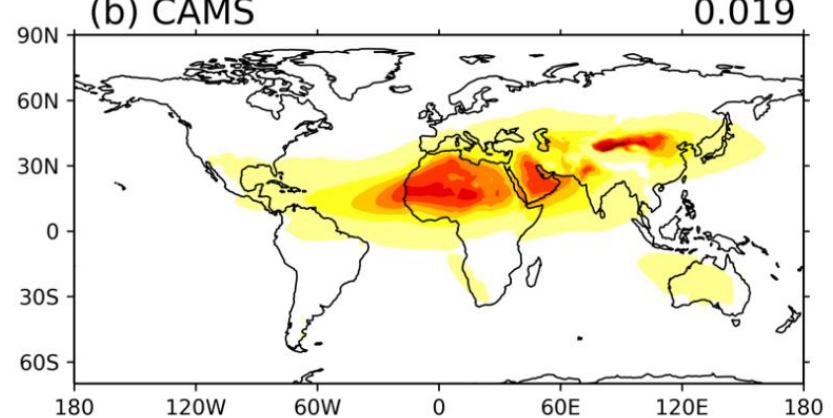

(c) MERRA2

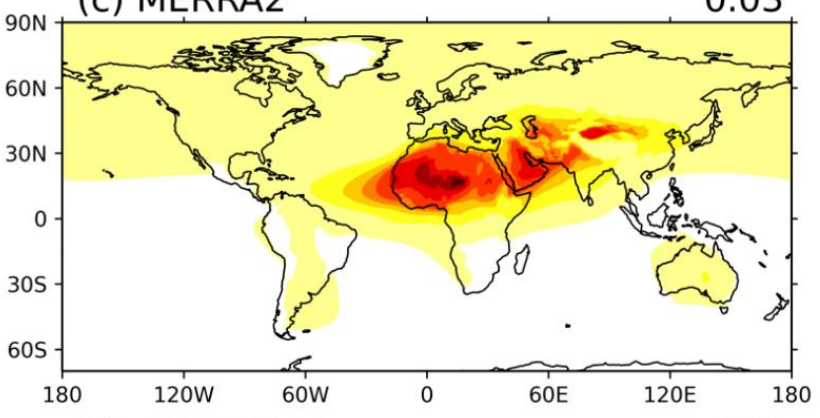

(d) AMIP MEM

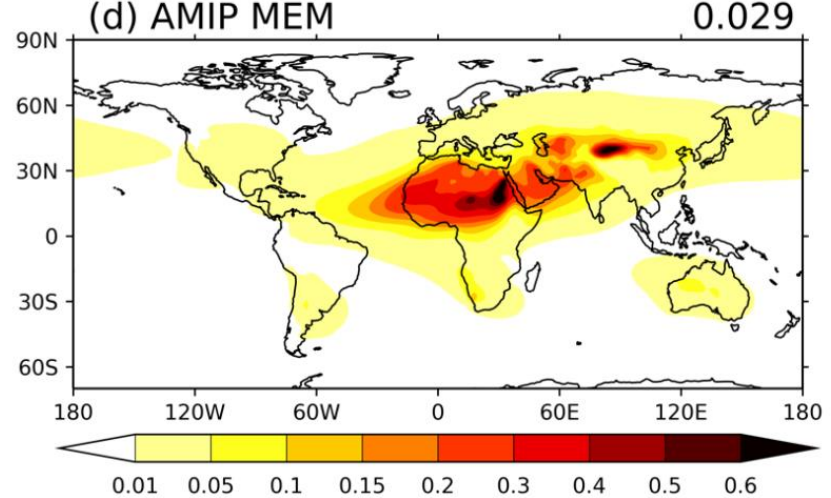

(e) MIDAS vS. AMIP MEM

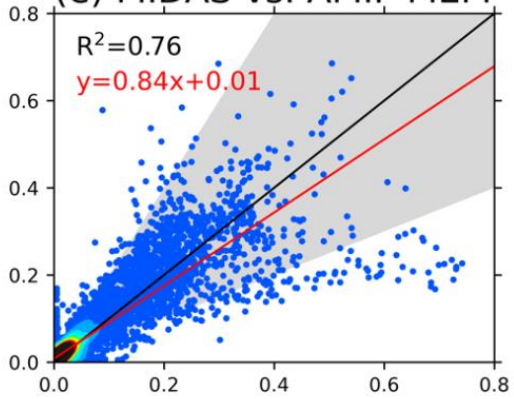

(f) CAMS vs. AMIP MEM

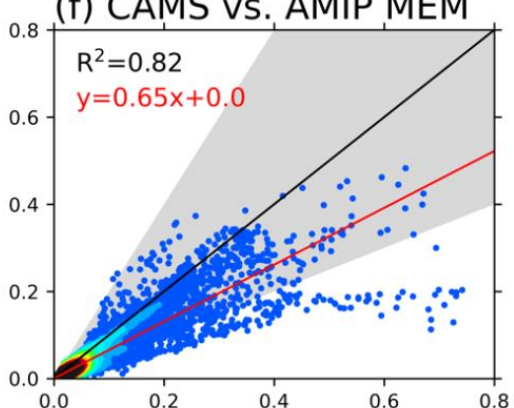

(g) MERRA2 vs. AMIP MEM

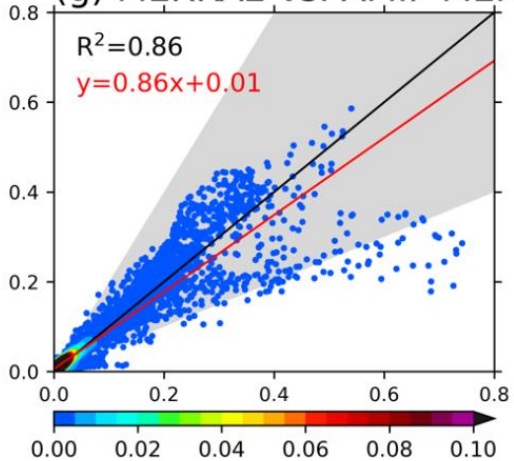

(h) Model performances

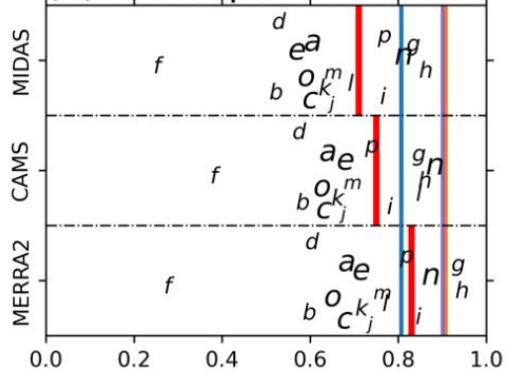

Figure 11: Intercomparison of 2005-2014 annual mean DOD from (a) MIDAS, (b) CAMS, (c) MERRA2 and (d) AMIP MEM.

(e-g) show the density $\left(10^{-4}\right)$ scatter plots of observation/reanalyses (a-c; y-axes) vs. AMIP MEM (d; $x$-axes): the black lines are the 1:1 correspondence while the red lines are the linear fitting $\left(\mathrm{R}^{2}\right.$ and the regression equation given at top left corners). (h) is a summary of the performance of each individual model measured by the spatial $\mathrm{R}^{2}$ (X-axis) between each individual model and observation/reanalyses. Models are shown by letters (cf. Table 1). The red vertical bars denote where the AMIP MEM stands. The blue vertical bar shows the spatial $\mathrm{R}^{2}$ between CAMS and MIDAS. Similarly, orange bars for MERRA2 vs. MIDAS, and purple for CAMS vs. MERRA2. 
(a) DOD $<=0.1$
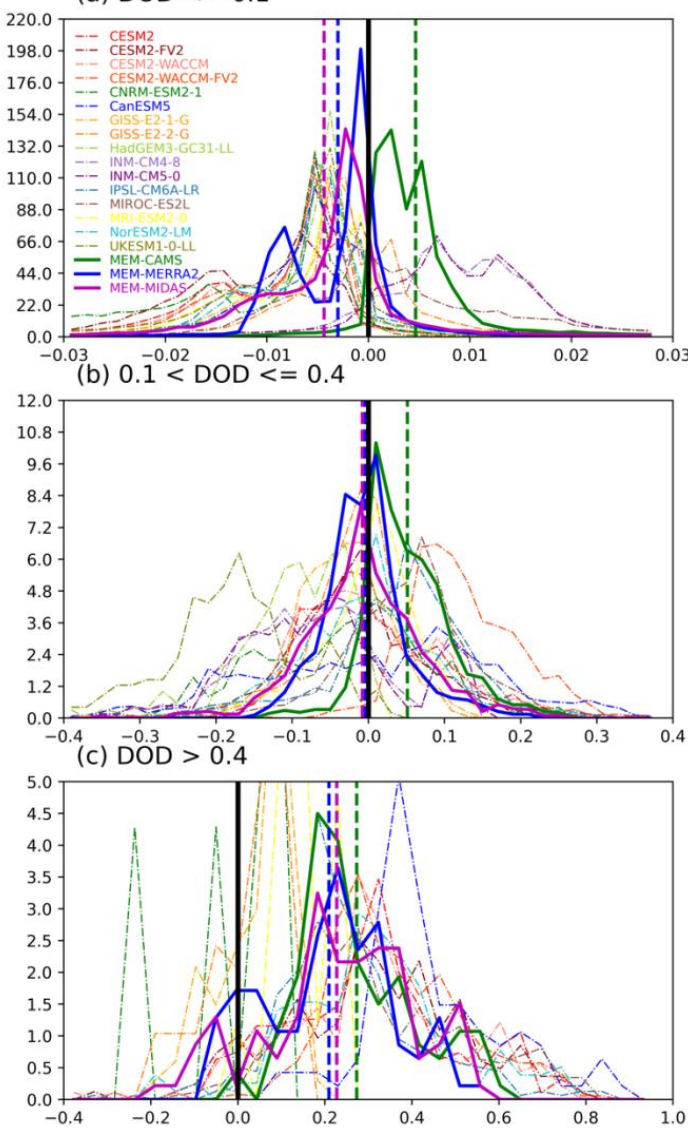

(d) DOD zonal mean \& regional distribution (\#)

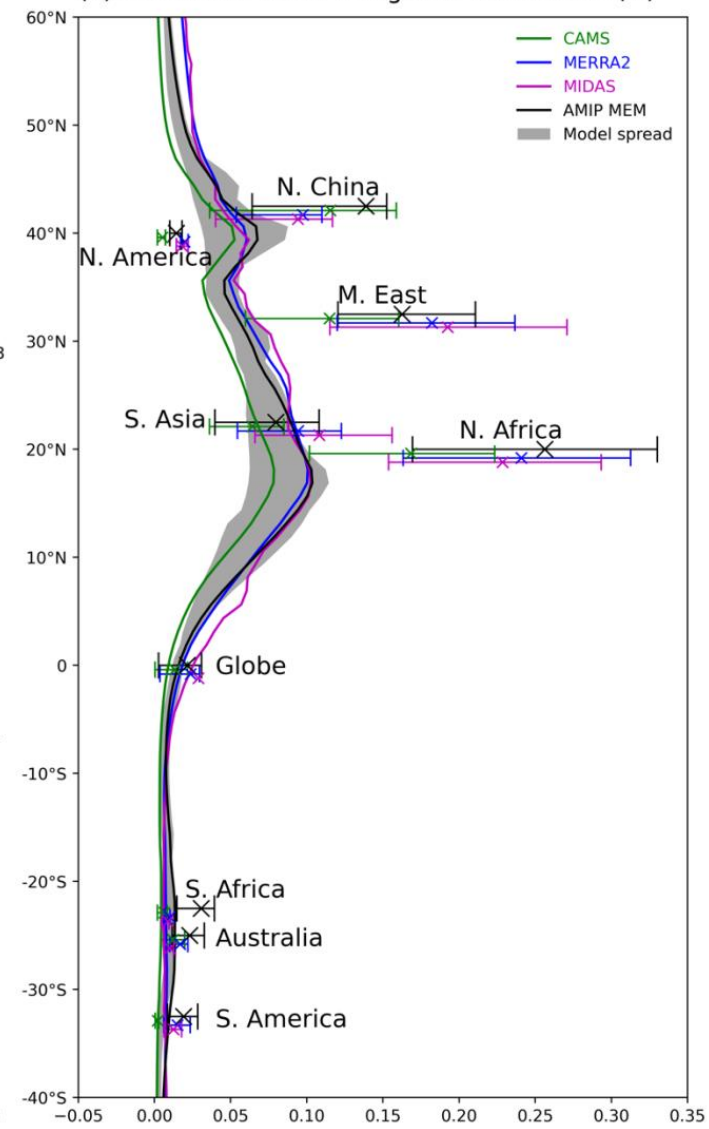

Figure 12: (a-c) The probability density distribution of models to observation/reanalyses DOD differences in three categories, sampled by a size bin of 0.005 . Solid green curves are AMIP MEM minus CAMS, solid blue curves for AMIP MEM minus MERRA2, and solid purple curves for AMIP MEM minus MIDAS. The dashed vertical lines denote the mean of the distributions. The dashed curves represent individual models minus MIDAS. The distribution is calculated using 10 years (2005-2014) of monthly mean data from all grid cells that lie in the corresponding DOD category. The DOD categories refer to AMIP MEM and individual models where applicable. Negative values indicate a model underestimation of DOD. (d) zonal mean DOD profiles (curves; grey shading for $10^{\text {th }}-90^{\text {th }}$ percentiles of multi-model spread) and regional mean distributions

(error-bars for $10^{\text {th }}-90^{\text {th }}$ percentile spreads and crosses in the middle for mean values of 2005-2014 annual mean) over the eight dust source regions. 
https://doi.org/10.5194/acp-2021-578

Preprint. Discussion started: 13 September 2021

(c) Author(s) 2021. CC BY 4.0 License.
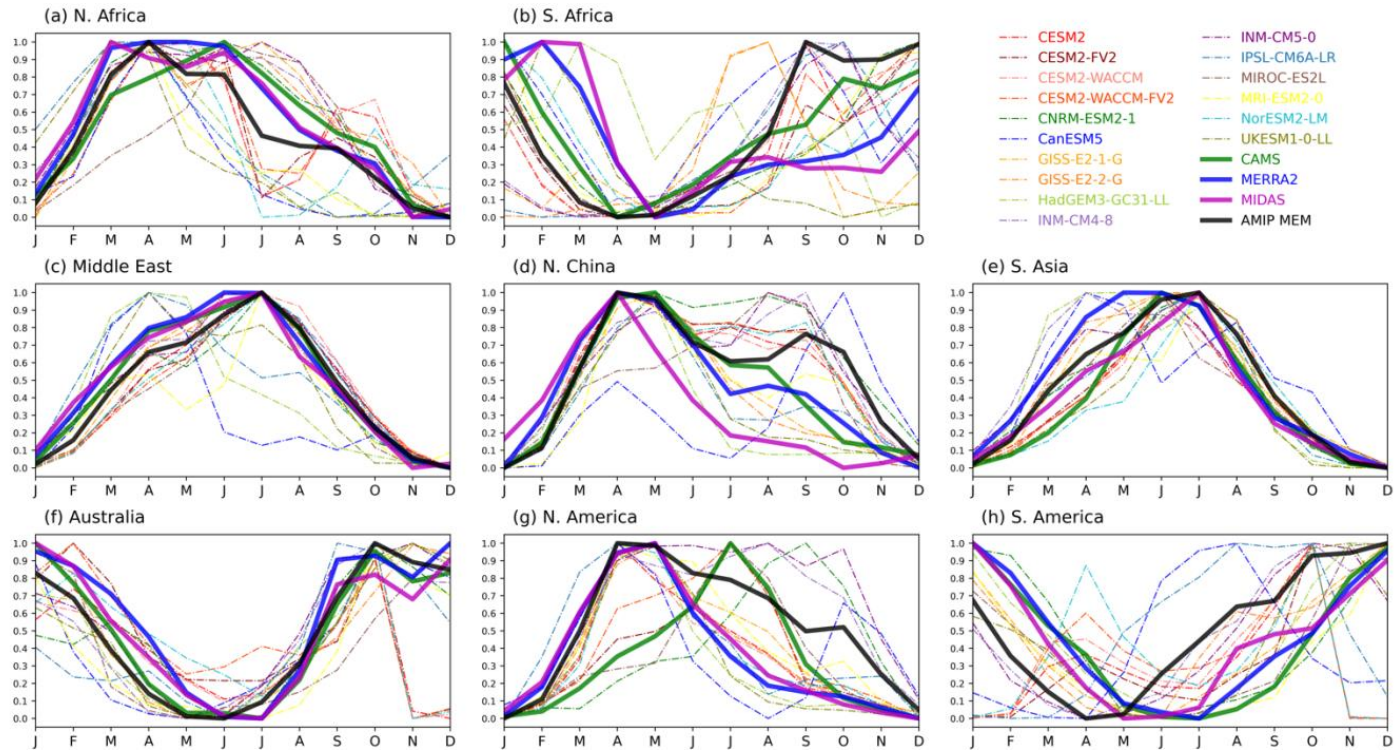

Figure 13: Seasonal cycles of DOD over the eight dust source regions. Dashed curves represent individual models, with the AMIP MEM in solid black. Also shown are results from CAMS (solid green), MERRA2 (solid blue) and MIDAS (solid purple). Each curve is normalized against its minimum and maximum. The absolute DOD seasonal cycles are included in Supplementary Figure S8. 